\title{
Article \\ Heat Transfer Enhancement of Small-Diameter Two-Phase Closed Thermosyphon Using Cellulose Nanofiber and Hydrophilic Surface Modification
}

\author{
Dongnyeok Choi ${ }^{1}$, Gyosik Jun ${ }^{2}$, Woonbong Hwang ${ }^{2, *}$ and Kwon-Yeong Lee ${ }^{1, *(D)}$ \\ 1 Department of Mechanical and Control Engineering, Handong Global University, 558 Handong-Ro, \\ Heunghae-eup, Buk-gu, Pohang-si 37554, Korea; cdn4400@gmail.com \\ 2 Department of Mechanical Engineering, Pohang University of Science and Technology (POSTECH), \\ 77 Cheongam-ro, Nam-gu, Pohang-si 37673, Korea; ksjeon8385@postech.ac.kr \\ * Correspondence: whwang@postech.ac.kr (W.H.); kylee@handong.edu (K.-Y.L.); Tel.: +82-54-260-1176 (K.-Y.L.)
}

Citation: Choi, D.; Jun, G.; Hwang, W.; Lee, K.-Y. Heat Transfer

Enhancement of Small-Diameter Two-Phase Closed Thermosyphon Using Cellulose Nanofiber and Hydrophilic Surface Modification. Nanomaterials 2021, 11, 647. https:// doi.org/10.3390/nano11030647

Academic Editor: Javier Navas

Received: 4 February 2021

Accepted: 2 March 2021

Published: 6 March 2021

Publisher's Note: MDPI stays neutral with regard to jurisdictional claims in published maps and institutional affiliations.

Copyright: (c) 2021 by the authors. Licensee MDPI, Basel, Switzerland. This article is an open access article distributed under the terms and conditions of the Creative Commons Attribution (CC BY) license (https:/ / creativecommons.org/licenses/by/ $4.0 /)$.

\begin{abstract}
In this study, we observed the Geyser phenomenon that occurs in a small-diameter twophase closed thermosyphon (confinement number of 0.245 ). This phenomenon interferes with the natural circulation of the internal working fluid and increases the thermal resistance of the system. This study attempts to improve the thermal performance of the system using cellulose nanofiber as the working fluid and hydrophilic surface modification at the inner surface of the evaporator section. As a result, the total thermal resistance showed average reduction rates of $47.51 \%, 36.69 \%$, and $22.56 \%$ at filling ratios of $0.25,0.5$, and 0.75 , respectively.
\end{abstract}

Keywords: two-phase closed thermosyphon; confinement effect; geyser phenomenon; cellulose nanofluid; hydrophilic surface modification

\section{Introduction}

Due to the depletion of petroleum energy and distrust of the stability of nuclear energy, the need for eco-friendly energy is emerging. Unlike solar photovoltaic energy systems that convert light energy into electrical energy, solar thermal energy cannot collect heat high enough to run a turbine that collects electricity, but it can make hot water for use. For hot water production, a medium is needed to collect solar heat and deliver it to water. Two-phase closed thermosyphon (TPCT) is the most frequently used heat transfer medium for solar heat collection. As TPCT uses the latent heat of boiling and condensation of working fluid, its thermal resistance is low. Therefore, the amount of heat transfer is significant despite an insignificant temperature difference [1]. However, due to the operation principle, the uprising vapor and down-falling condensate collide. If the channel diameter of the TPCT is insufficiently small, stagnation occurs in the middle of the channel, thereby reducing the heat transfer performance significantly. This phenomenon is known as the confinement effect [2-4]. By reducing the diameter of the TPCT and installing more TPCT, it is possible to collect a larger amount of solar heat in the same area of space. The confinement number (Co), which is the relevant dimensionless number, is the ratio of the capillary length (or Laplace length, $\lambda_{c}$ ) of the working fluid to the channel diameter $\left(D_{i}\right)$, as shown in Equation (1) below.

$$
\text { Co }=\frac{\lambda_{C}}{D_{i}}=\frac{\sqrt{\frac{\sigma}{\left(\rho_{l}-\rho_{v}\right) g}}}{D_{i}}
$$

where $\sigma, \rho_{l}, \rho_{v}$, and $g$ refer to surface tension, density of water, density of vapor, and acceleration of gravity, respectively.

Previous studies showed that Co less than 0.12 implies a conventional TPCT that does not exhibit the confinement effect. In a TPCT with $0.12<\mathrm{Co}<0.34$, the confinement effect 
occurs and fails repeatedly, which is known as the Geyser phenomenon [2-7]. In a TPCT with Co > 0.34, the stagnation of the working fluid does not diminish but continues; this is known as the entrance limit [8]. When this phenomenon occurs, the heat of the evaporator is not transferred effectively and dry out occurs rapidly; therefore, it can no longer be a heat transfer medium [8]. Choi and Lee [9] designed a TPCT experiment apparatus with a channel that satisfied $\mathrm{Co}=0.245$ using deionized (DI) water as the working fluid. They observed that the temperature at the evaporator surface oscillated regularly with a large amplitude in the steady state, thereby confirming the Geyser phenomenon. In addition, cellulose nanofiber (CNF) fluid was used instead of DI water as the working fluid, and it was confirmed that the critical heat flux (CHF) and boiling heat transfer coefficient (BHTC) of the system improved. Among boiling studies involving nanofluids, most studies reported improved CHF [10-14]. However, various results of the BHTC have been reported. Some studies reported the "deposition" of nanoparticles on the heater surface, which improved the BHTC $[10,11]$. Other studies revealed a thick "coating" of nanoparticles on the heater surface, resulting in an increase in thermal resistance and a decrease in the BHTC [12,15]. Other studies showed the change in the BHTC of the nanofluid case was slight compared to that of water $[13,14]$. In addition, Suriyawong and Wongwises studied pool boiling using $\mathrm{TiO}_{2}$ nanofluid and reported that its $\mathrm{BHTC}$ was higher and lower than that of water in low and high concentration nanofluids, respectively [16]. It was discovered that the high conductivity of nanoparticles enhanced the BHTC at the low concentration; however, the higher the concentration, the thicker the coating of nanoparticles on the heater surface, resulting in a higher thermal resistance. In contrast, in a wire pool boiling study by Choi and Lee [9] using CNF fluid, the BHTC was lower than that of water at low concentrations $(0.07,0.1 \mathrm{wt} \%)$, but higher at high concentrations $(0.3,0.5 \mathrm{wt} . \%)$. Figure 1 shows the scanning electron microscopy (SEM) images of the wire surface after each experiment [9]. As shown, an extremely thin coating had formed on the wire surface. However, the coating thickness did not change by concentration. This was due to the characteristics of $\mathrm{CNF}$, in which the particles do not aggregate with each other [17]. At low concentrations, the thermal resistance increased with the thin coating. As the concentration increased, the thickness of the coating remained the same, but the bubble frequency generated on the wire surface accelerated [9] and heat transfer was enhanced.

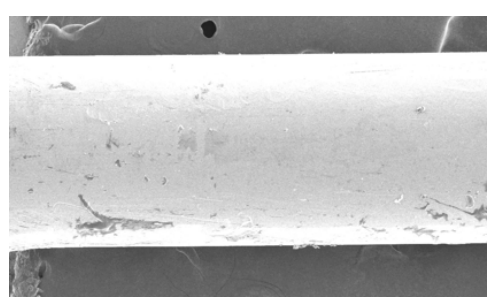

(a) Water

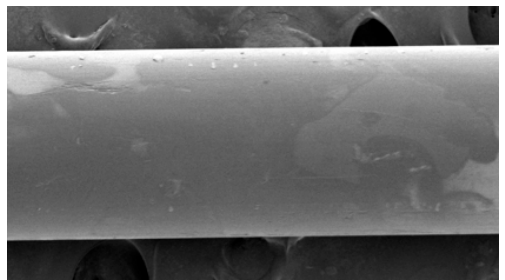

(b) $0.075 \mathrm{wt} \% \mathrm{CNF}$

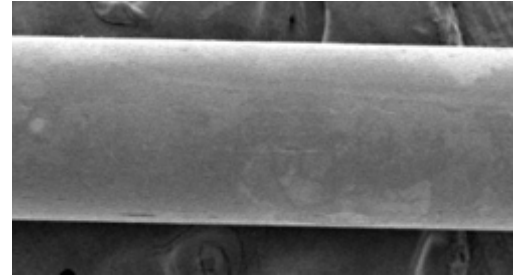

(c) $0.3 \mathrm{wt} \% \mathrm{CNF}$

Figure 1. Scanning electron microscopy (SEM) image of wire after the experiment.

In this study, to enhance the heat transfer performance of the TPCT of Co $=0.245$, hydrophilic surface modification was additionally applied to the evaporator inner surface in addition to the CNF fluid. Previous studies have attempted to improve the heat transfer coefficient of conventional TPCT $(\mathrm{Co}<0.11)$ by reducing the wettability of the condenser inner surface [18-20] or improving the wettability of the evaporator's inner surface $[18,19,21]$. In this study, because the focus was on improving the boiling heat transfer performance, surface modification was applied only to the evaporator's inner surface. In addition, the large Reynolds number of the cooling water flowing through the cooling jacket, which served as a heat sink for the condenser section, was applied. It had a sufficient cooling capacity, resulting in the temperature change on the condenser inner surface being insufficient during the TPCT operation. 


\section{Materials and Methods}

\subsection{Cellulose Nanofiber (CNF)}

$\mathrm{CNF}$ is an eco-friendly organic nanofiber (purchased from A\&Poly) and is manufactured using commercial coffee filters based on the method proposed by the Isogai group [17]. The measured properties of the $0.5 \mathrm{wt} \%$ CNF fluid were as follows (Table 1). It had aa neutral acidity of $\mathrm{pH} 7.42$ and electrical conductivity of $1.658 \mathrm{mS} / \mathrm{cm}$, which was much higher than that of DI water at $0.0005 \mathrm{mS} / \mathrm{cm}$. Its density was $0.9984 \mathrm{~g} / \mathrm{cm}^{3}$, which did not indicate a significant difference from that of DI water of $0.9970 \mathrm{~g} / \mathrm{cm}^{2}$; however, the viscosity was $0.0089 \mathrm{Ns} / \mathrm{m}^{2}$, which was slightly larger than that of DI water at $0.00089 \mathrm{Ns} / \mathrm{m}^{2}$. In existing inorganic nanofluids, nanoparticles aggregate and settle over a significant period of time, which is disadvantageous [22,23]. CNF has an extremely low zeta potential $(-92.83 \mathrm{mV}$ at $0.5 \mathrm{wt} \%)$ and is negatively charged in solution; therefore, it affords the advantage of minimal aggregation or sedimentation between particles [17].

Table 1. Properties of the $0.5 \mathrm{wt} \%$ cellulose nanofiber (CNF) fluid and de-ionized water.

\begin{tabular}{ccc}
\hline Property & CNF $\left(\mathbf{0 . 5}\right.$ w.t $\left.\%, \mathbf{~ 2 5}^{\circ} \mathbf{C}\right)$ & De-Ionized Water $\left(\mathbf{2 5}{ }^{\circ} \mathbf{C}\right)$ \\
\hline $\mathrm{pH}$ & 7.42 & 7 \\
\hline Conductivity $[\mathrm{mS} / \mathrm{cm}]$ & 1.658 & 0.0005 \\
\hline Density $\left[\mathrm{g} / \mathrm{cm}^{3}\right]$ & 0.9984 & 0.9970 \\
\hline Viscosity $\left[\mathrm{N}-\mathrm{s} / \mathrm{m}^{2}\right]$ & 0.0089 & 0.00089 \\
\hline Fiber Width $[\mathrm{nm}]$ & $1-20$ & - \\
\hline Zeta Potential $[\mathrm{mV}]$ & -92.83 & $-30 \sim-40$ \\
\hline
\end{tabular}

As the CNF supplied by the manufacturer was in the form of a gel with a concentration of $2 \mathrm{wt} \%$, the appropriate amount of DI water was added to obtain the desired concentration of CNF fluid. For an effective dispersion of the CNF in the added water, an ultrasonic homogenizer (HUH-606, Hantech) was used to perform ultrasonic dispersion for $30 \mathrm{~min}$. The density and surface tension required for the calculation of Co were assumed to be the same as those of DI water. In fact, the density of the $0.5 \mathrm{wt} \% \mathrm{CNF}$ fluid and DI water exhibited a difference error of $0.14 \%$. Although the surface tension could not be measured because of the absence of measuring equipment, it was assumed that the error (e.g., of the density) with DI water would not be large because $0.5 \mathrm{wt} \%$ is an extremely low concentration.

\subsection{Hydrophilic Surface Modification}

The chemical surface treatment process shown in Figure 2 was performed to apply hydrophilic surface confinement to the evaporator channel. The surface treatment process is as follows. First, to surface-modify only the inner surface of the copper tube, an acidresistant tape was applied to the outer surface of the copper tube to prevent contact with the chemicals. Subsequently, the tube was etched by immersing it in a solution in which a $70 \%$ nitric acid $\left(\mathrm{HNO}_{3}\right)$ solution and distilled water were mixed at a volume ratio of 1:1 for approximately $1 \mathrm{~min}$ at room temperature. The etched tube was washed thoroughly with distilled water so that no chemical solution remained on the surface. Subsequently, the tube was immersed in a mixture of $2.5 \mathrm{M}$ sodium hydroxide $(\mathrm{NaOH})$ solution and $0.13 \mathrm{M}$ ammonium persulfate $\left(\left(\mathrm{NH}_{4}\right)_{2} \mathrm{~S}_{2} \mathrm{O}_{8}\right)$ solution for $40 \mathrm{~min}$, and the solution was maintained at a temperature of $4{ }^{\circ} \mathrm{C}$ in a refrigerator before and during the immersion. After the surface treatment, the tube was washed with distilled water, and the acid-resistant tape on the outer surface of the tube was removed. After washing the inside/outside of the tube again, it was dried in an oven at $60^{\circ} \mathrm{C}$ for more than $1 \mathrm{~h}$ to completely remove the moisture. 


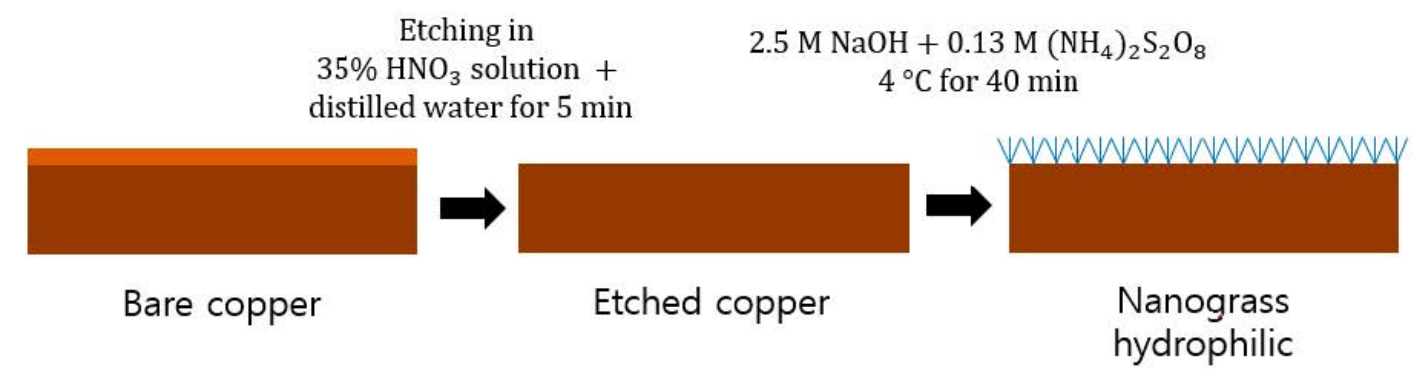

Figure 2. Fabrication process of the nanograss hydrophilic copper tube.

The contact angle of the surface droplets and the microstructure of the surface were photographed to verify the wettability of the surface-modified specimen. As surface modification was applied to the inner surface of the small-diameter tube, it was difficult to photograph the surface. For a smooth image capture, a plate specimen (measuring $50 \mathrm{~mm}$ (length) $\times 5 \mathrm{~mm}$ (width) $\times 1 \mathrm{~mm}$ (thickness)) produced by applying the same surface treatment method to the same material was used. The contact angle of the water droplet was measured using a measuring device (Smartdrop, FEMTOFAB) by depositing $5 \mu \mathrm{L}$ of water droplets on the plate specimen. As shown in Figure 3, the hydrophilic surface had a small contact angle of $8.8^{\circ}$, which was significantly smaller than the contact angle of the convex droplet on a bare surface $\left(71.7^{\circ}\right)$. The nanostructure of the specimen surface was photographed using SEM (JEOL 7401F, JEOL) (Figure 4). As shown, unlike the smooth bare copper plate, a nanoscale structure was formed on the modified surface. Copper hydroxide has rod-like structures that are several micrometers in length and 1000-2000 nm in diameter, as shown in the SEM image.

\subsection{Experimental Apparatus}

Figure 5 [9] shows a schematic illustration and photograph of the TPCT used in the experiment. The dimensions of the TPCT are as follows. When the working fluid was DI water, the inner diameter of the channel to satisfy $\mathrm{Co}=0.245$ was $11 \mathrm{~mm}$. The lengths of the evaporator, adiabatic, and condenser sections were 300,150, and $400 \mathrm{~mm}$, respectively. Due to the heat-resisting limitation of the copper heater, an input power of 0-800 W was applied. The inner surface area of the evaporator section was set so that the heat flux was similar to the average input heat flux range $\left(0-80 \mathrm{~kW} / \mathrm{m}^{2}\right)$ of previous studies. As the diameter of the channel can be determined by considering $\mathrm{Co}_{\mathrm{o}}$, the length of the evaporator section was set by considering the heat flux range; hence, it was set to $300 \mathrm{~mm}$. Figure 6 shows a comparison of the lengths of the evaporator and condenser sections of this study and those of previous studies. As shown, the length of the evaporator section set in this study $(300 \mathrm{~mm})$ was an approximate average value compared with those of previous studies. To maximize the condensation performance and maintain the temperature of the condenser section through the rapid condensation of steam, the condenser section was set to the maximum length that did not deviate significantly from those of other studies. The length of the adiabatic section was the average value obtained from previous studies. 


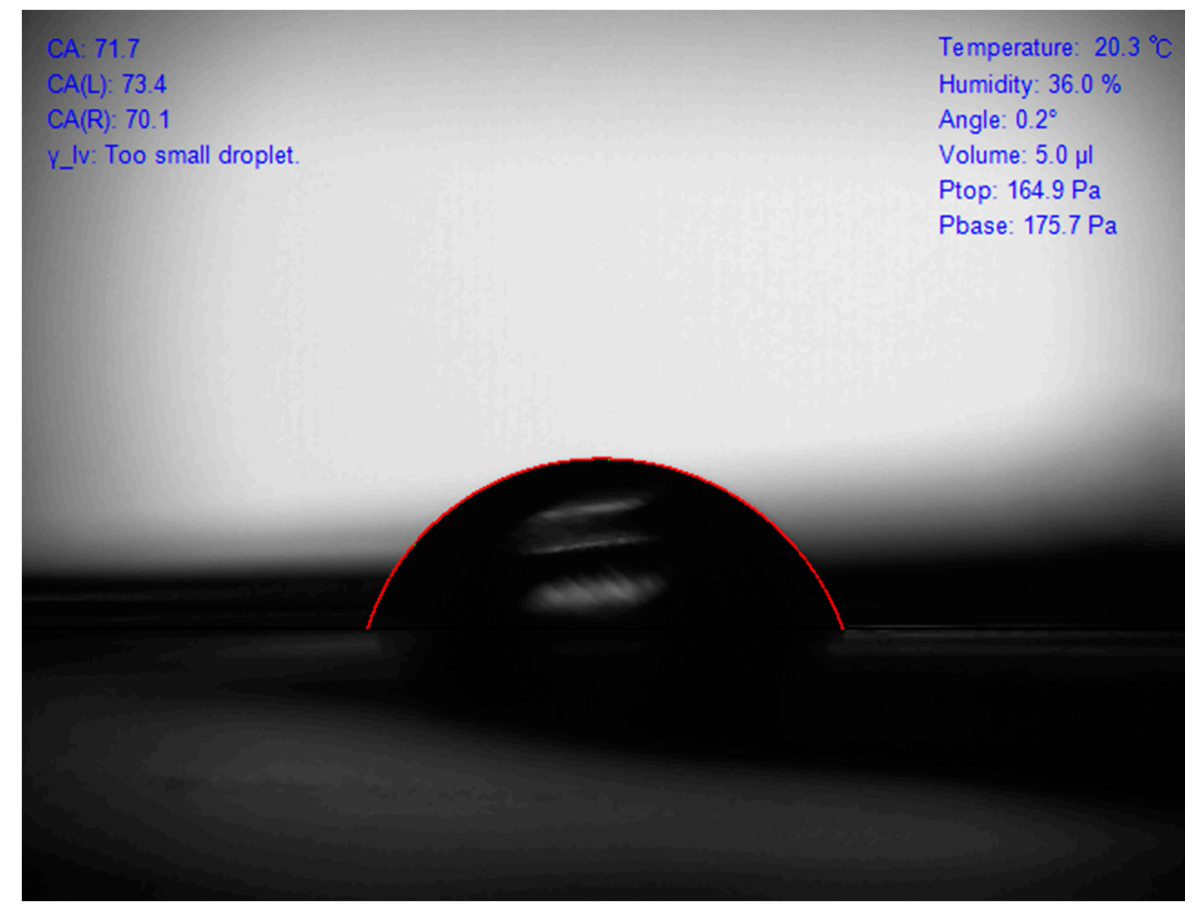

(a) Bare surface

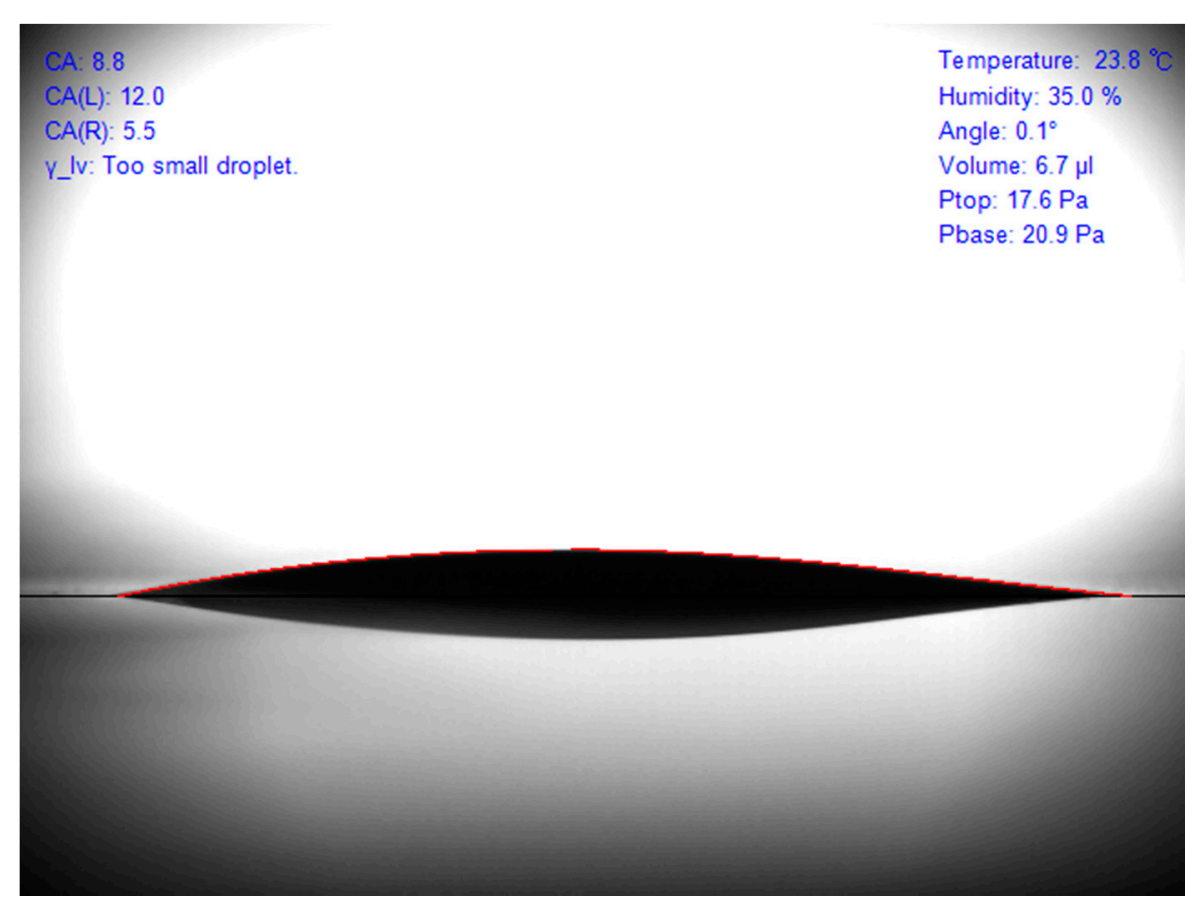

(b) Hydrophilic surface

Figure 3. Surface contact angle of the copper surface. 

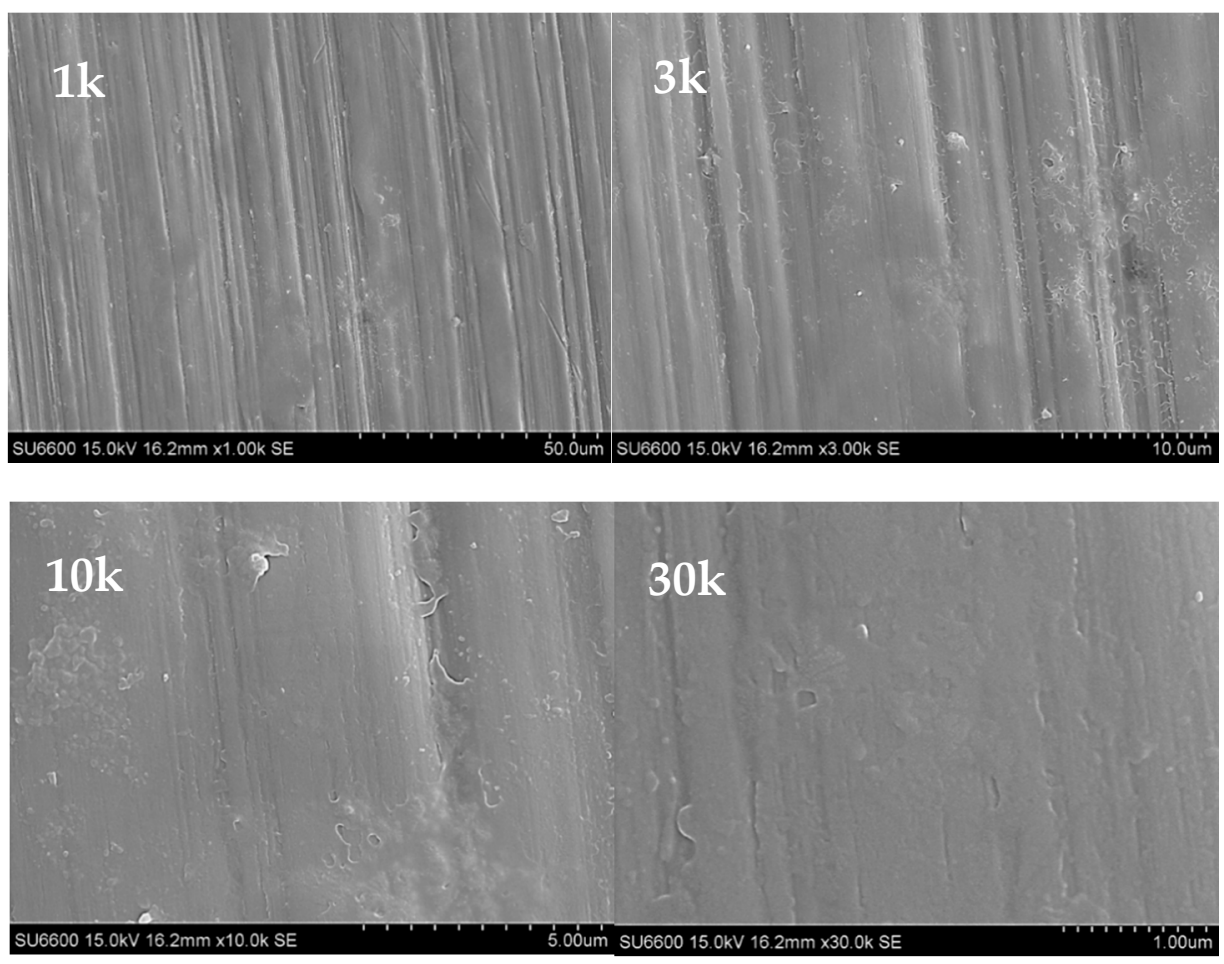

(a) Bare surface
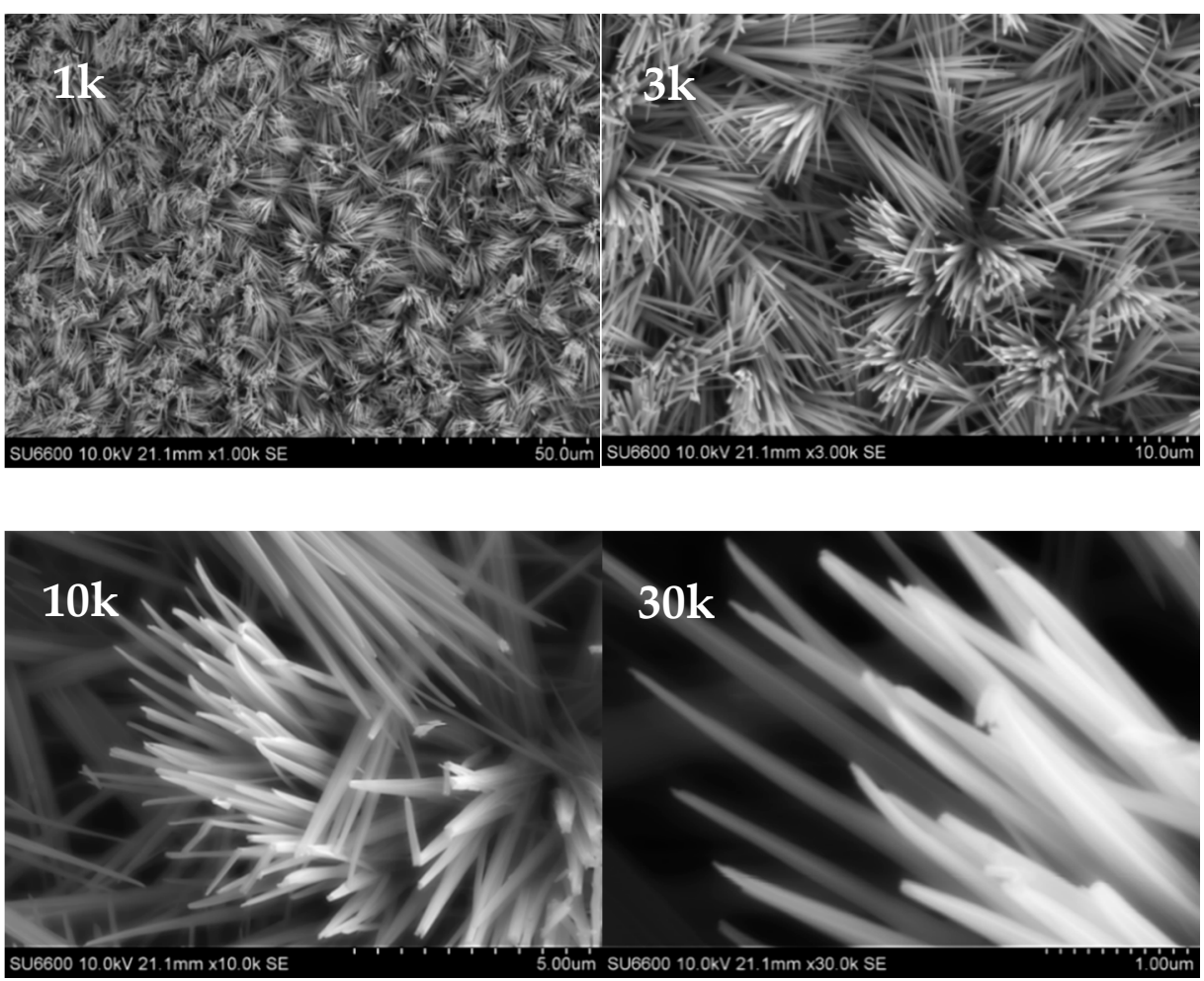

(b) Hydrophilic surface

Figure 4. SEM image of the copper surface. 

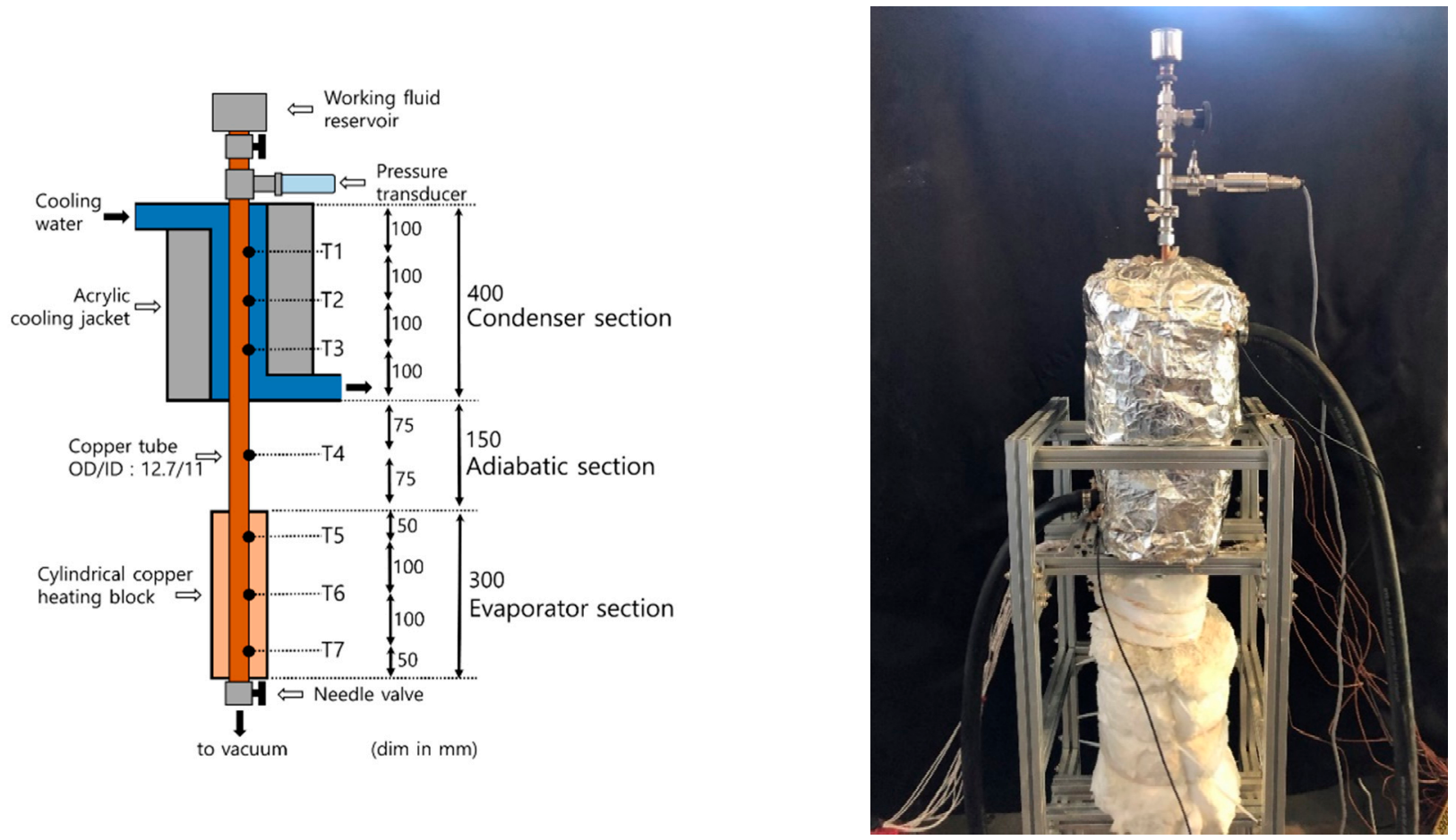

Figure 5. Experimental apparatus [9].

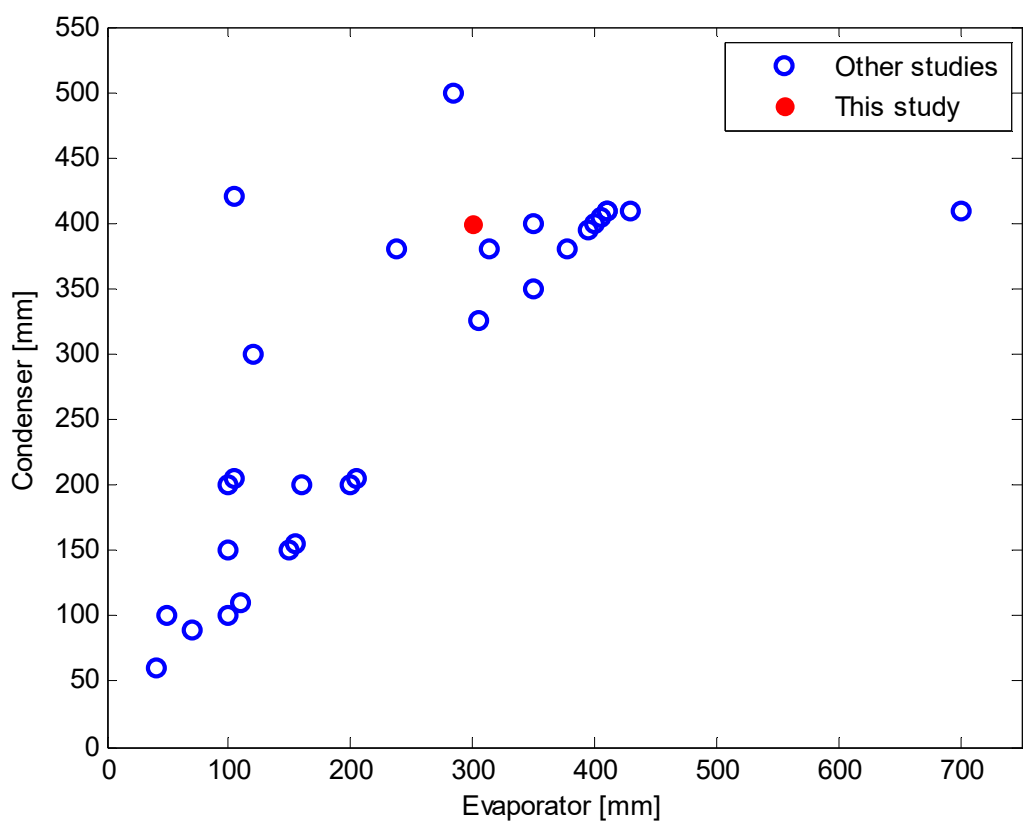

Figure 6. Length of the evaporator and condenser of two-phase closed thermosyphon (TPCT) in previous studies.

The material of the channel as well as that of the heater that supplied heat to the evaporator channel were copper. The heater was connected to a power supply (N8953A, Keysight) to power the copper heater. The contact thermal resistance between the evaporator channel and copper heater was minimized by filling aluminum nitride powder of thermal conductivity $150 \mathrm{~W} / \mathrm{mK}$. The condenser was cooled by the cooling water flowing through the cooling jacket. The cooling jacket, which was made of acrylic, was supplied with cooling water at a specified temperature and flow rate from the connected chiller (GR-C-00050A, Busung). Subsequently, 3, 2, and 3 k-type thermocouples (Omega) 
were attached to the evaporator, adiabatic, and condenser section channel outer surface, respectively. All of these thermocouples were precisely calibrated to exhibit an error of $\pm 0.15^{\circ} \mathrm{C}$. The temperature data of the thermocouples were collected at $1 \mathrm{~s}$ intervals using a data acquisition system (34970A, Keysight) connected to the thermocouples. At the upper end of the condenser section, a pressure transmitter (PSHJ1000TCTJ) with an error rate of $\pm 0.15 \%$ was attached to measure the internal vacuum pressure. A ceramic fiber insulator with a thermal conductivity of $0.049 \mathrm{~W} / \mathrm{mK}$ (at $200{ }^{\circ} \mathrm{C}$ ) and thickness of 10,5 , and $5 \mathrm{~cm}$ was applied to the evaporator, adiabatic, and condenser sections, respectively. As the outer surface temperature of the insulation material showed an error of less than $2{ }^{\circ} \mathrm{C}$ from the room temperature during the actual experiment, we could assume that it was completely insulated (the outer surface temperature of the copper heater was $500-800{ }^{\circ} \mathrm{C}$ ).

The experimental process was as follows: The vacuum pump connected to the valve at the bottom of the apparatus was operated to an inside vacuum of 0.02 bar, and then the valve was closed. Subsequently, the valve installed at the top of the apparatus was opened, and a specific amount of working fluid was injected (filling ratios (FRs) of $0.25,0.5$, and 0.75). Subsequently, power was applied to the heater using the power supply. The input power was increased from 100 to $800 \mathrm{~W}$ at $100 \mathrm{~W}$ intervals. Each input power was supplied for a sufficient time (approximately $45 \mathrm{~min}$ ) to reach the steady state, and temperature data were collected at $1 \mathrm{~s}$ intervals. Subsequently, the BHTC and total thermal resistance were calculated using Equations (3) and (4):

$$
Q_{\text {in }}=V \cdot I,
$$

where $Q_{\text {in }}$ was calculated using the data record voltage, $V$, and current, $I$.

$$
h_{e}=\frac{Q_{i n}}{A_{e, i}\left(\bar{T}_{e, i}-\bar{T}_{s a t}\right)},
$$

where $\bar{T}_{e, 5}, \bar{T}_{e, 6}$, and $\bar{T}_{e, 7}$ refer to the average value of $\mathrm{T}_{e, 5}, \mathrm{~T}_{e, 6}$, and $\mathrm{T}_{e, 7}$, respectively, for $500 \mathrm{~s} ; \bar{T}_{e, i}$ is the average value of $\bar{T}_{e, 5}, \bar{T}_{e, 6}$, and $\bar{T}_{e, 7} ; \bar{T}_{s a t}$ refers to the average value of $\mathrm{T}_{s a t}$ for $500 \mathrm{~s}$ (the saturation temperature of the working fluid based on the saturation pressure inside the channel obtained through the pressure transducer).

$$
R_{t o t}=\frac{\bar{T}_{e, i}-\bar{T}_{c, i}}{Q_{i n}}
$$

where $\bar{T}_{e, i}$ and $\bar{T}_{c, i}$ refer to the average inner surface temperature of the evaporator and condenser channel, respectively.

Table 2 shows the uncertainty of each measurement equipment used in the experiment. Table 3 shows the uncertainty of each experimental result obtained using the uncertainty calculation formula, Equation (5) [24]. The maximum uncertainties of the input heat and total thermal resistance were $0.28 \%$ and $10.67 \%$, respectively, indicating errors of within $15 \%$. The uncertainty of the BHTC was primarily less than $15 \%$. However, two points indicated uncertainties exceeding $15 \%$; hence, their BHTC data were discarded.

$$
\delta f=\sqrt{\sum_{i=1}^{n}\left(\frac{\partial f}{\partial x_{i}} \delta x_{i}\right)^{2}}
$$


Table 2. Uncertainty of measuring device.

\begin{tabular}{cccc}
\hline Measurement & Device & Uncertainty & Range \\
\hline Wall Temperature & Thermocouple (K-type, Omega) & $\pm 0.15^{\circ} \mathrm{C}$ & $0-700{ }^{\circ} \mathrm{C}$ \\
Pressure & Pressure transducer (PSHJ1000TCTJ, Sensys) & $\pm 0.15 \%$ & $0-100 \mathrm{kPa}(\mathrm{Abs})$. \\
Voltage \& Current & Power supply (N8953A, Keysight) & $\pm 0.2 \%$ & $0-200 \mathrm{~V}, 0-75 \mathrm{~A}$ \\
Coolant Temperature & Chiller (GR-C-00050A, Busung) & $\pm 0.15^{\circ} \mathrm{C}$ & $-10-30{ }^{\circ} \mathrm{C}$ \\
Coolant Flow Rate & Flowmeter (Yuyu inst.) & $\pm 1 \%$ & $0-0.7 \mathrm{~kg} / \mathrm{s}$ \\
Thermal Power & Copper heater (Woori heater) & $\pm 0.2 \%$ & $0-800 \mathrm{~W}$ \\
\hline
\end{tabular}

Table 3. Uncertainty of experimental result.

\begin{tabular}{ccc}
\hline Result & Symbol & Uncertainty \\
\hline Input Power $[\mathrm{W}]$ & $Q_{\text {in }}$ & $0.28 \%$ \\
Boiling Heat Transfer Coefficient $\left[\mathrm{kW} / \mathrm{m}^{2}\right]$ & $h_{e}$ & $4.68-14.46 \%$ \\
Total Thermal Resistance $[\mathrm{K} / \mathrm{W}]$ & $R_{\text {tot }}$ & $2.39-10.67 \%$ \\
\hline
\end{tabular}

\section{Result and Discussion}

\subsection{Geyser Phenomenon}

Figure 7a-d show the inner surface temperature of the evaporator channel at FR 0.25 based on the working fluid (DI water and CNF fluid) and surface condition, respectively. At $100 \mathrm{~W}$ input power, all cases shown in Figure 7a-d indicated the Geyser phenomenon, in which the confinement effect repeated, and the temperature graph showed large amplitudes and long oscillation periods. In particular, in case (c), the oscillation period was significantly longer. At $200 \mathrm{~W}$ input power, cases (a) and (b) indicated the fast Geyser phenomenon, as mentioned by Choi and Lee [9], where the amplitude was the same as that of the Geyser phenomenon, but the period was shorter. However, in case (c), the temperature did not increase immediately; instead, it delayed slightly and then increased. This is because, in the FR 0.25 experiment, thin-film evaporation was more dominant than pool boiling on the inner wall of the channel, and the hydrophilic surface rewetted faster compared with the bare surface. In case (d), the period was reduced again and the amplitude was reduced significantly compared with case (c) because of the fast heat transfer due to the CNF.

The BHTC and total thermal resistance can be calculated using the temperature difference between the average temperature of the evaporator's inner surface and the internal saturation temperature. At $100 \mathrm{~W}$ input power, the temperature differences of cases (a)-(d) were $13.01{ }^{\circ} \mathrm{C}, 7.58{ }^{\circ} \mathrm{C}, 3.75{ }^{\circ} \mathrm{C}$, and $2.15{ }^{\circ} \mathrm{C}$, respectively. At $200 \mathrm{~W}$ input power, the temperature differences of cases (a)-(d) were $21.60^{\circ} \mathrm{C}, 13.45^{\circ} \mathrm{C}, 10.53{ }^{\circ} \mathrm{C}$, and $4.81^{\circ} \mathrm{C}$, respectively. The temperature difference decreased gradually from cases (a) to (d); hence, the highest BHTC and lowest total thermal resistance are shown in (d). 

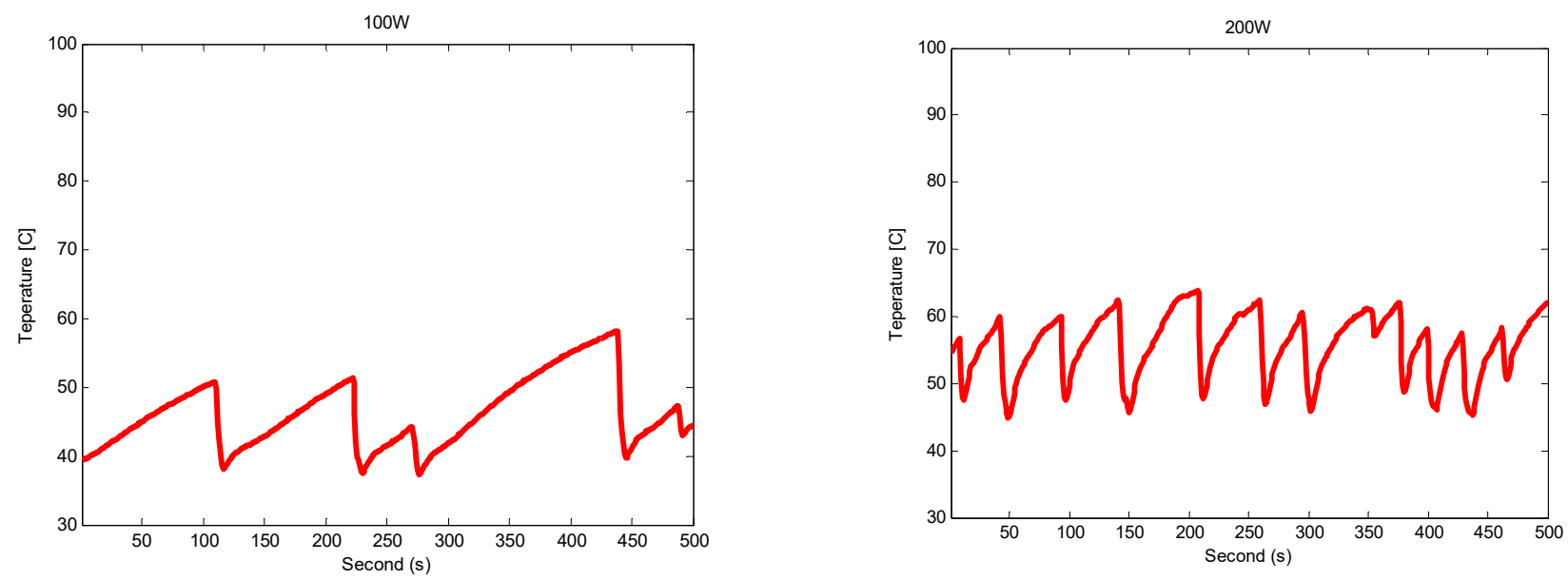

(a) DI water and bare surface [9] reproduced with permission from [Choi and Lee], [Applied Thermal Engineering]; published by [Elsevier], [2021].
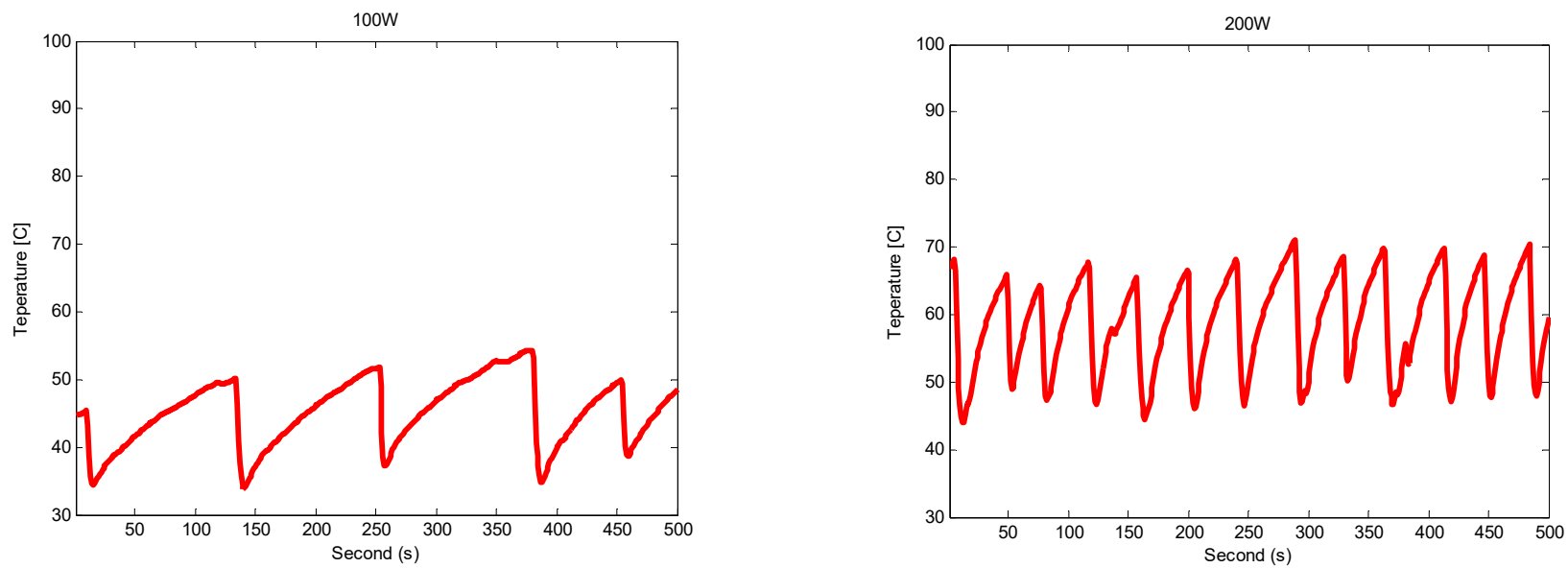

(b) CNF and bare surface
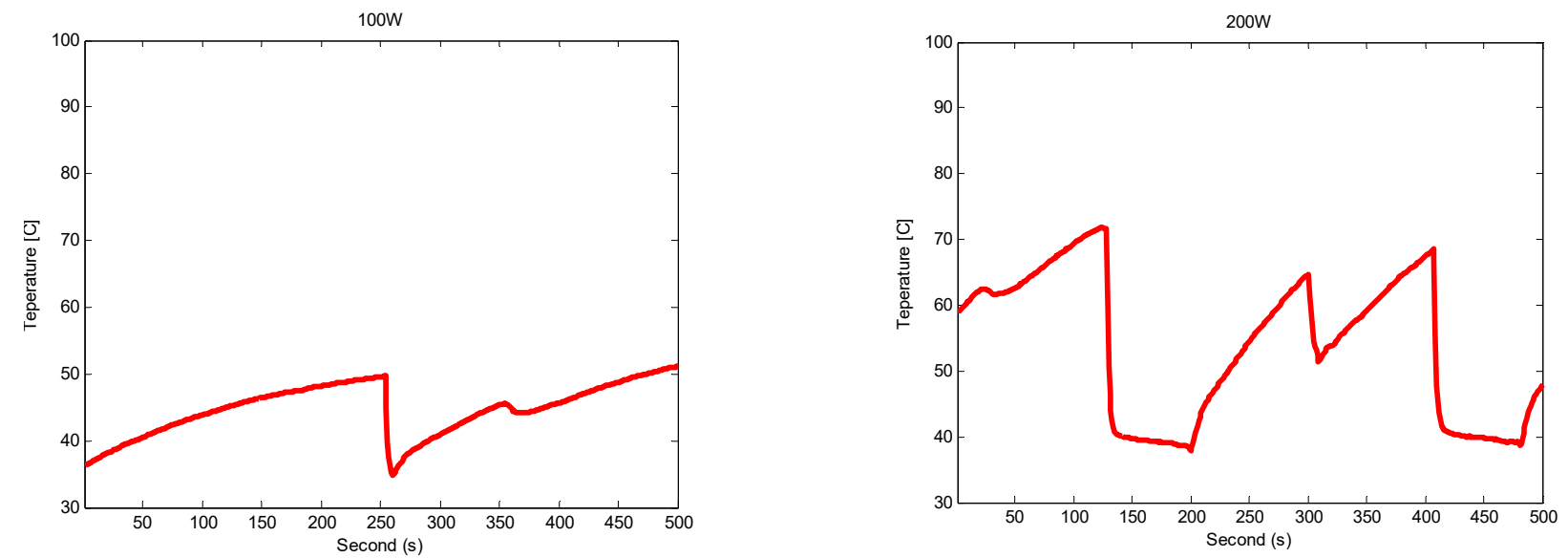

(c) DI water and superhydrophilic surface

Figure 7. Cont. 

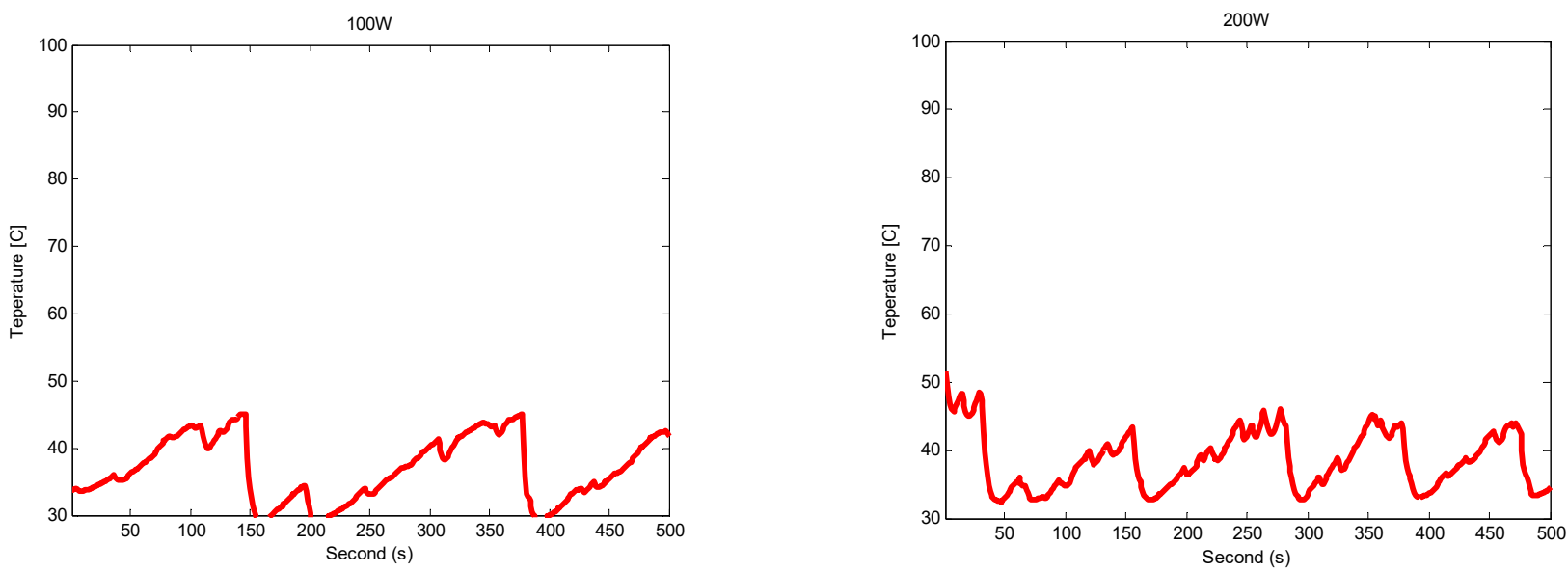

(d) CNF and hydrophilic surface

Figure 7. Evaporator wall temperature (T7) variations with time at FR 0.25.

\subsection{Hydrophilic Surface Modification}

Hydrophilic surface modification was applied to the TPCT evaporator section. In all the hydrophilic surface modification experiments, dry out did not occur up to an input power of $800 \mathrm{~W}$. When surface modification was not applied, dry out occurred at $700 \mathrm{~W}$. Hence, the CHF was improved by at least $14.3 \%$ compared with the bare tube case. At all FRs, the BHTC improved by at $31.09-246.87 \%$, and the average enhancement rates were $145.75 \%, 104.66 \%, 75.55 \%$, and $93.81 \%$ at FR $0.25,0.5,0.75$ (for test 1 ), and 0.75 (for test 2), respectively (Figure 8). The total thermal resistance of all FRs reduced (Figure 9), showing an average reduction rate of $32.39 \%, 31.21 \%, 17.5 \%$, and $20.22 \%$ at FR $0.25,0.5$, 0.75 (for test 1), and 0.75 (for test 2), respectively. The enhancement in the heat transfer performance was consistent with the basic theory that the evaporation performance of fluids on hydrophilic surfaces is better than that on bare surfaces. Furthermore, the CHF delayed due to the improved evaporation performance. In FR 0.75 test 1 and 0.75 test 2, the BHTC decreased rapidly at $200 \mathrm{~W}$. It appeared that the pool boiling was dominant at $100 \mathrm{~W}$ due to the large amount of working fluid, and the Geyser phenomenon appeared at $200 \mathrm{~W}$. In the first experiment, when going from $200 \mathrm{~W}$ to $300 \mathrm{~W}$, the boiling heat transfer coefficient increased sharply, and after $300 \mathrm{~W}$, the boiling heat transfer coefficient decreased slightly and then increased. In the second experiment, the boiling heat transfer coefficient increased relatively slowly between $200 \mathrm{~W}$ and $400 \mathrm{~W}$, and after $400 \mathrm{~W}$, the boiling heat transfer coefficient decreased slightly and then increased. Practically, it is difficult to reproduce $100 \%$ of the same phenomenon during repeated experiments because very complex heat and fluid flow occur inside the TPCT. Therefore, a slight difference occurs in the rising section of the boiling heat transfer coefficient in the first and second experiments, resulting in a $300 \mathrm{~W}$ point result of the first experiment appearing to be higher than those of the second experiment. In the case of the bare surface, BHTC rapidly dropped at $600 \mathrm{~W}$ of input power. This is because the temperature of the evaporator inner surface increased significantly because it was just before dry-out occurred at $700 \mathrm{~W}$. 


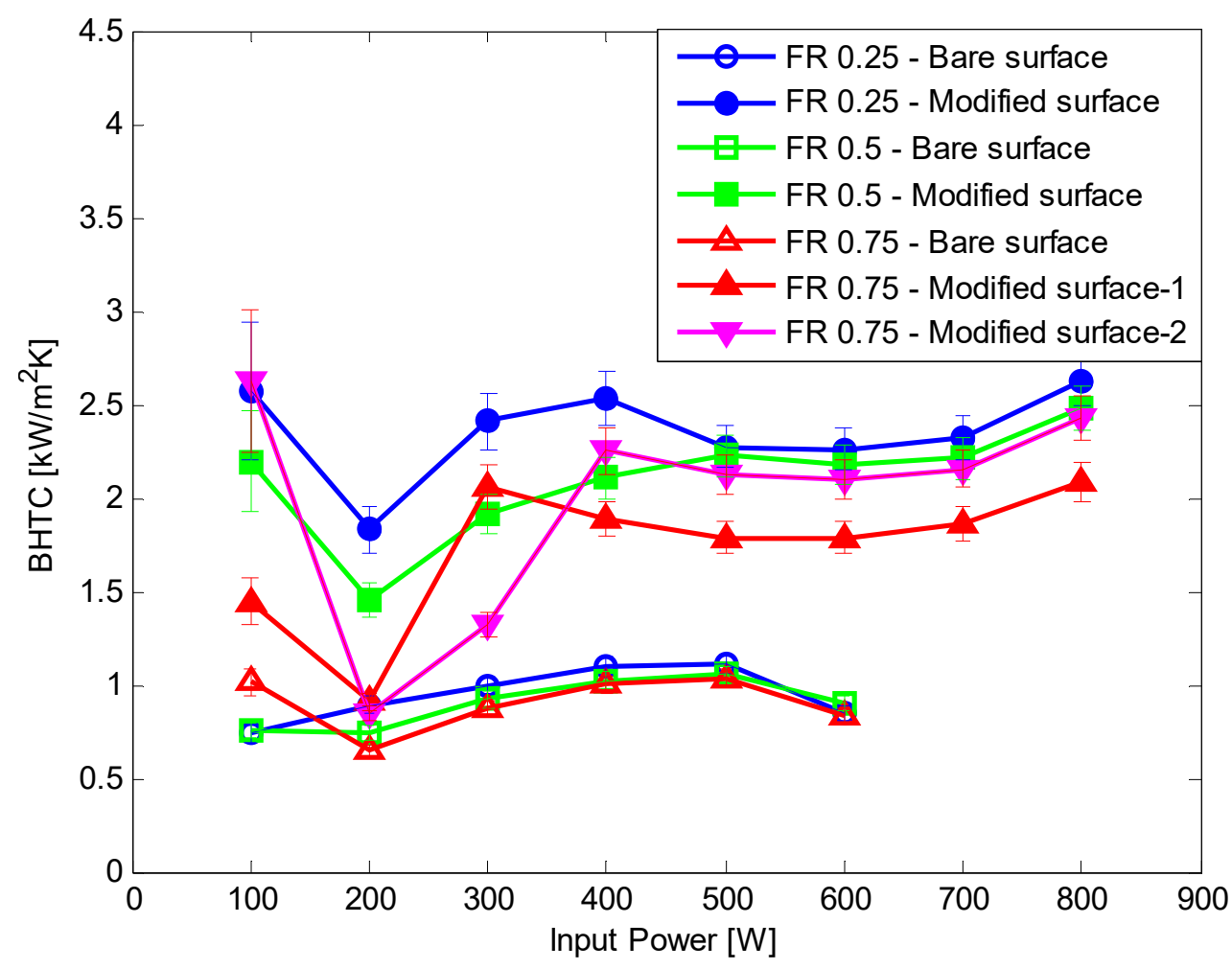

Figure 8. Comparison of the boiling heat transfer coefficient of bare and hydrophilic surfaces.

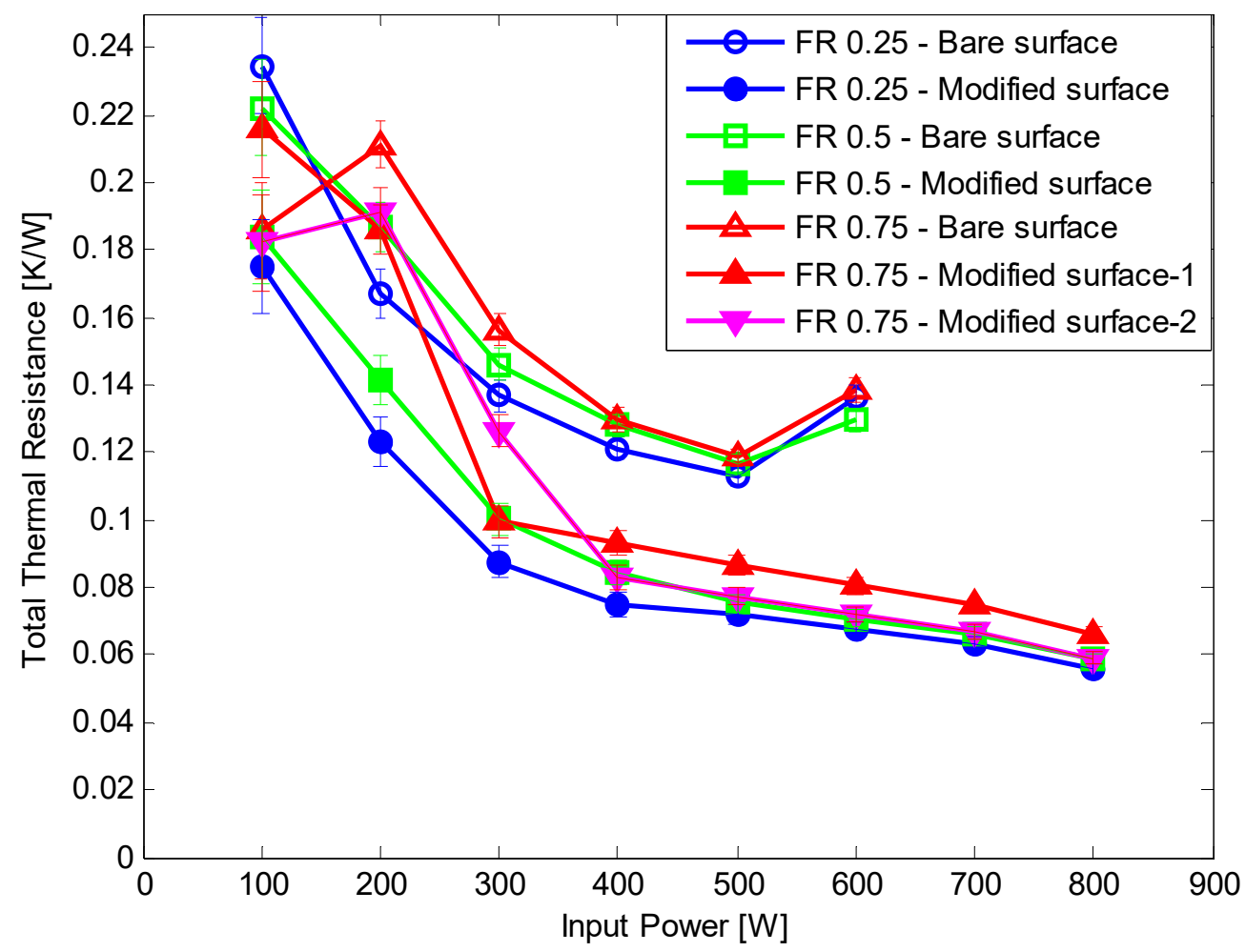

Figure 9. Comparison of the total thermal resistance of bare and hydrophilic surfaces. 


\subsection{CNF and Hydrophilic Surface Modification}

Both CNF fluid and hydrophilic surface modification were applied to the TPCT. At all FRs of $0.25,0.5$, and 0.75 , the CHF improved by more than $14.3 \%$ compared with the DI water and bare surface. The BHTC improved by up to $348.85 \%$ by $205.33 \%, 134.69 \%$, and $93.55 \%$ on average at FRs of $0.25,0.5$, and 0.75 , respectively (Figures $10-12$ ). The total thermal resistance showed average reduction rates of $47.51 \%, 36.69 \%$, and $22.56 \%$ at FRs of $0.25,0.5$, and 0.75 , respectively (Figures 10-12). This was the best result because the effect of the rapid generation of small-sized bubbles due to the CNF working fluid [9] and the result of Section 3.2 were combined. In FR 0.5 and 0.75, the BHTC decreased rapidly at $200 \mathrm{~W}$. It appeared that the pool boiling was dominant at $100 \mathrm{~W}$ due to the large amount of working fluid, and the Geyser phenomenon appeared at $200 \mathrm{~W}$. When the Gayser phenomenon occurs, a thin liquid film is formed on the inner surface of the boiling part of the TPCT, and heat transfer occurs through evaporation. When hydrophilic surface modification is applied, water supply to the evaporation surface becomes smooth due to the enhancement of the capillary ability of the hydrophilic surface, and thus evaporation heat transfer improves. In addition, CNF basically has a high hydration ability (watercontaining ability). As a result, it is estimated that when CNF is applied together, the evaporation heat transfer is improved by additionally supplying water as CNF remains on the evaporation surface. After the experiments, no aggregation and sedimentation of the CNF were observed.

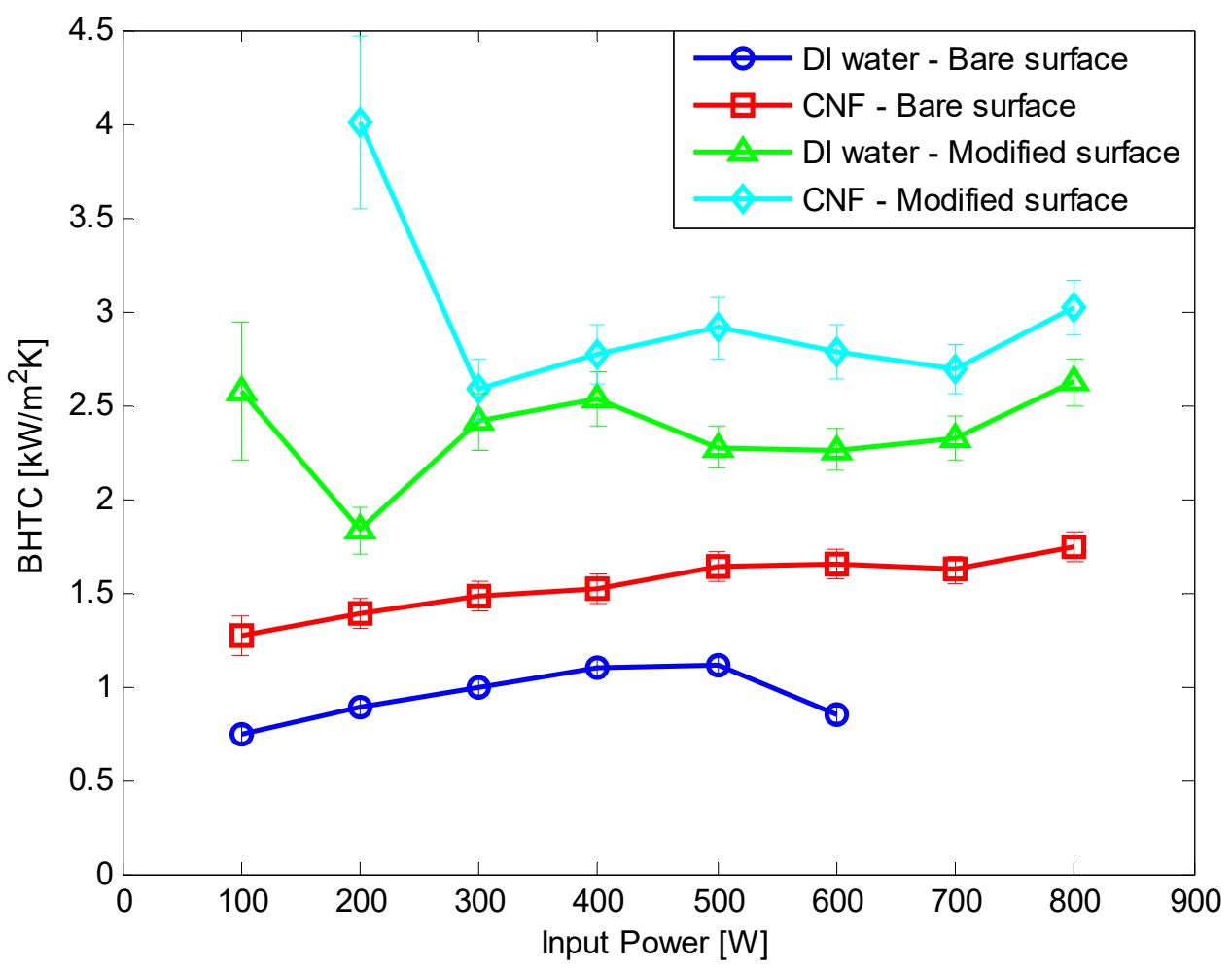

(a) Boiling heat transfer coefficient

Figure 10. Cont. 


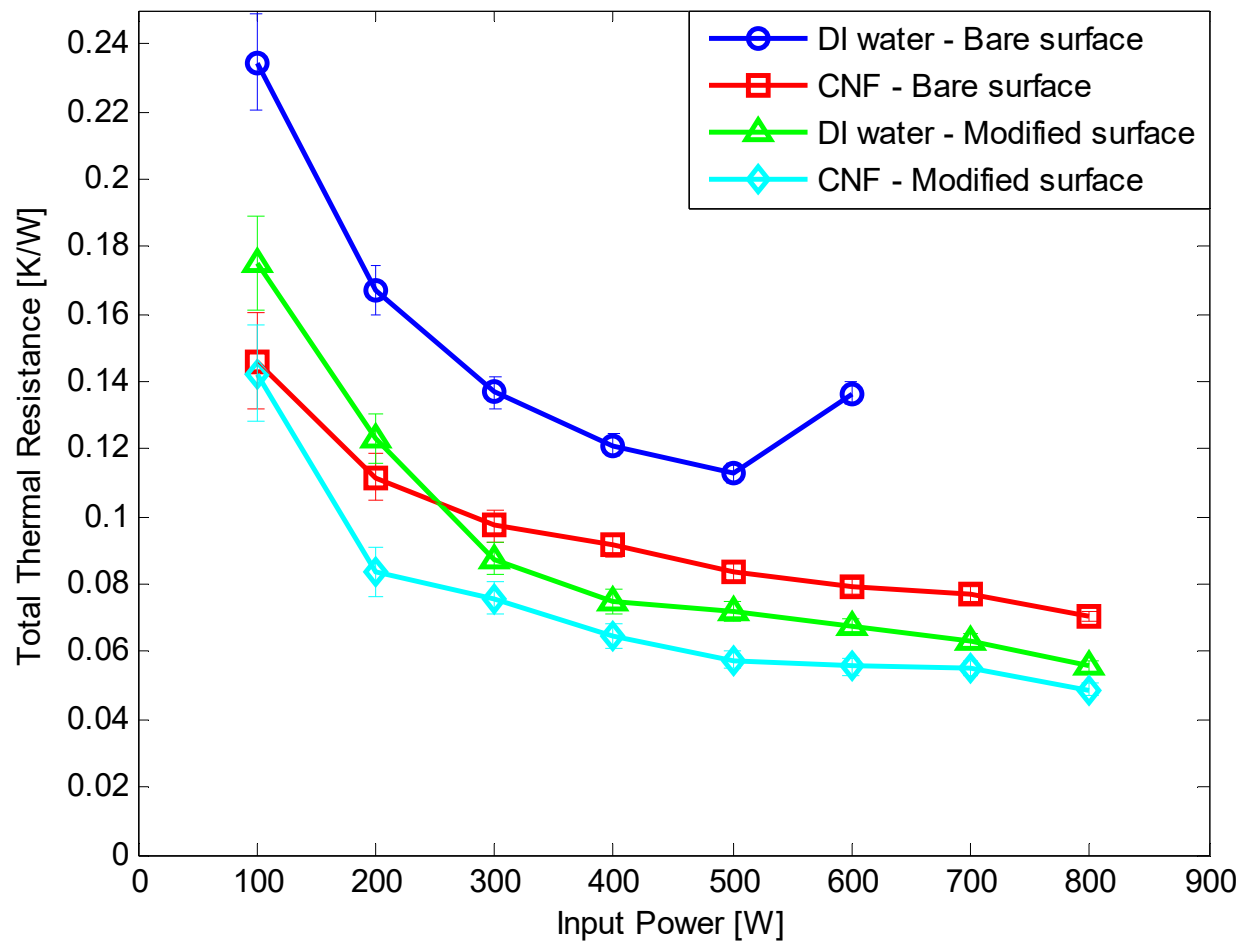

(b) Total thermal resistance

Figure 10. Comparison of experiment result at FR 0.25.

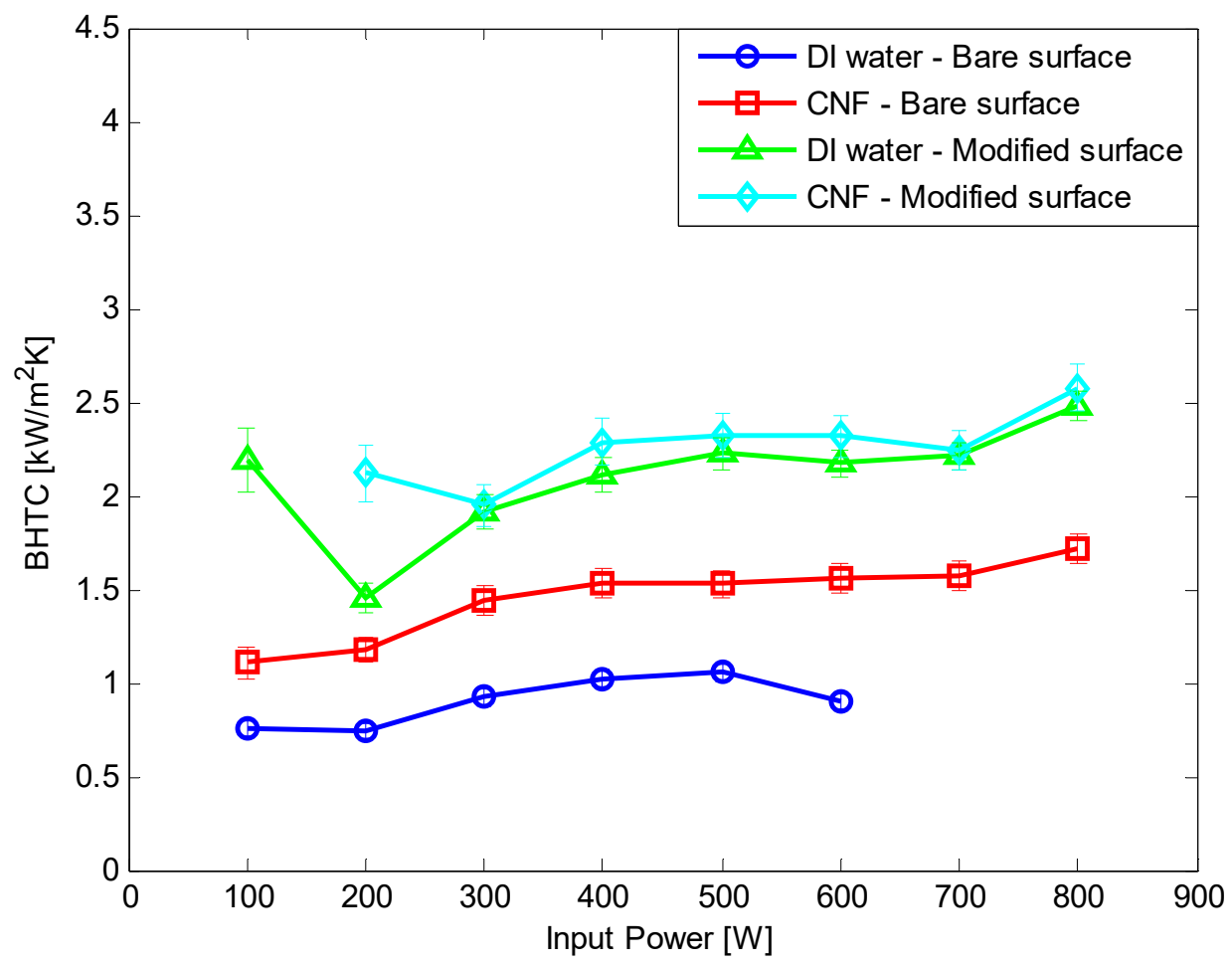

(a) Boiling heat transfer coefficient

Figure 11. Cont. 


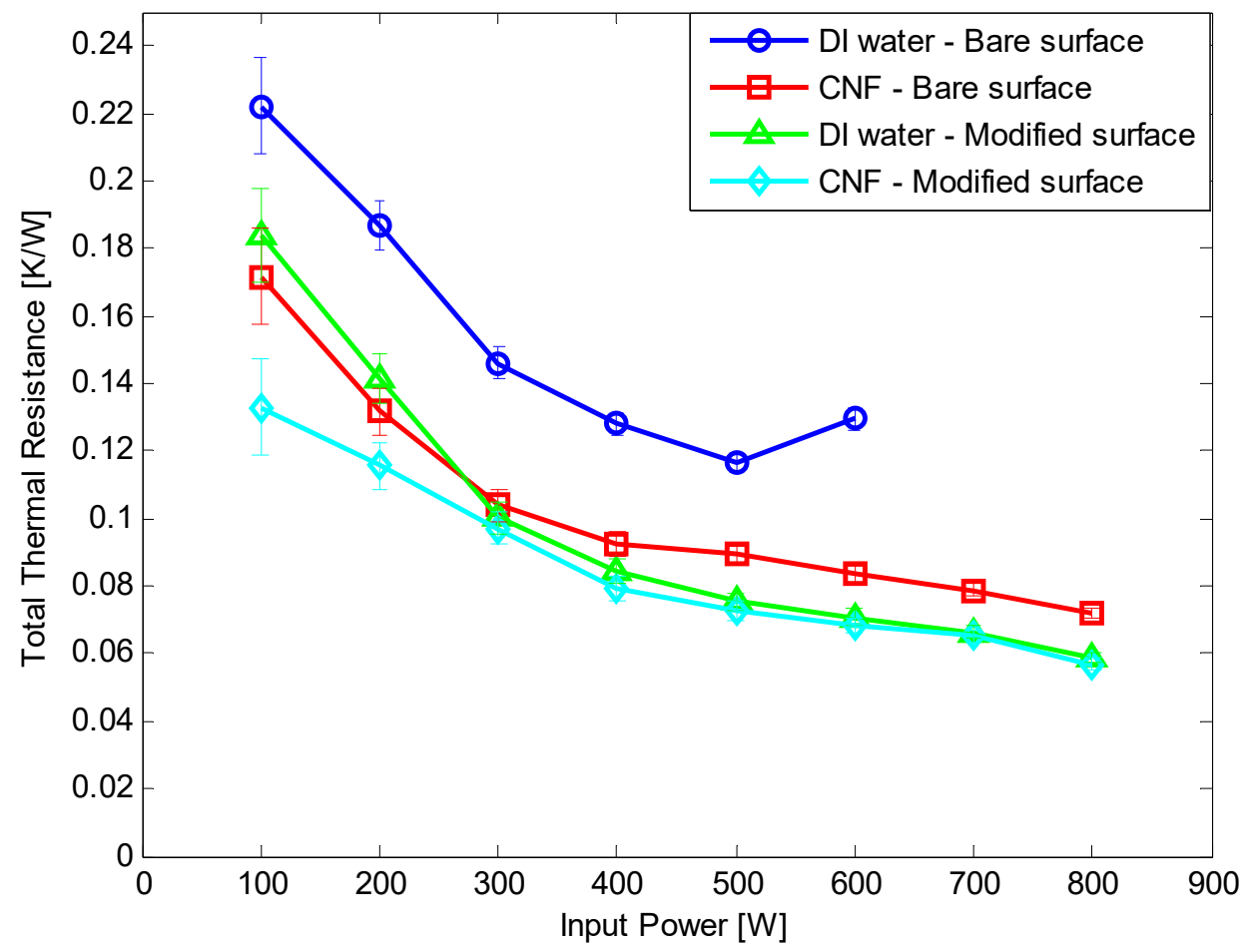

(b) Total thermal resistance

Figure 11. Comparison of experimental results at FR 0.5.

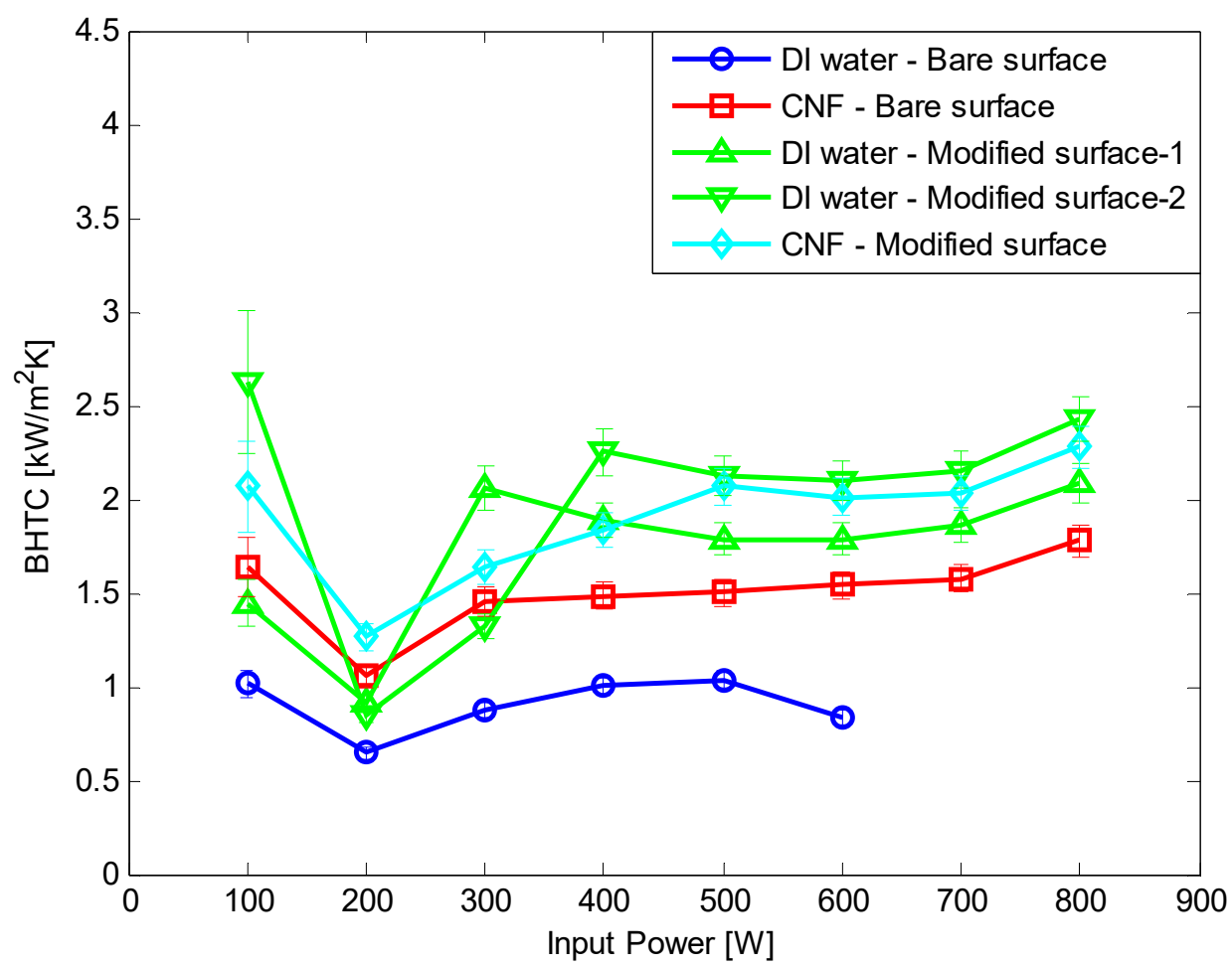

(a) Boiling heat transfer coefficient

Figure 12. Cont. 


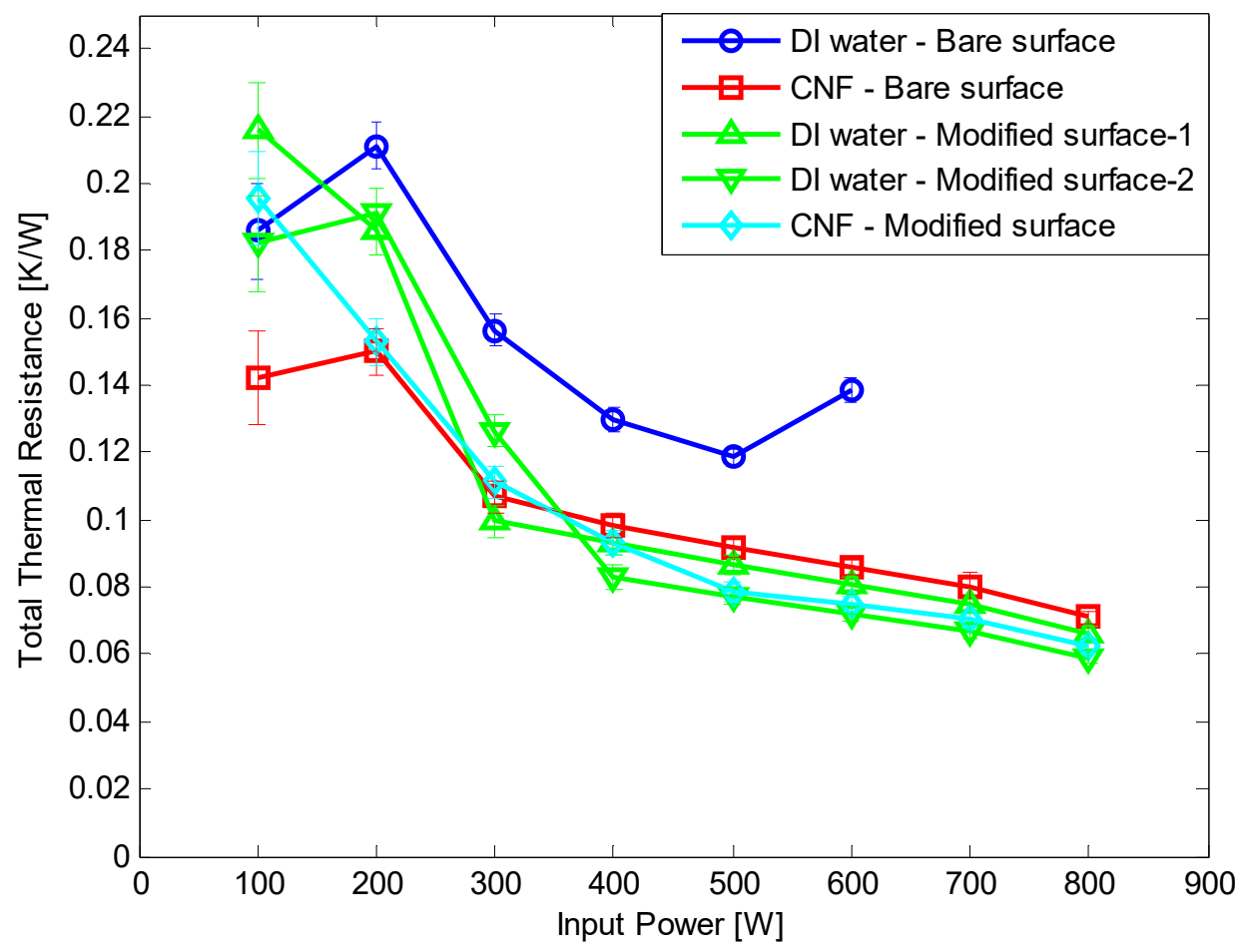

(b) Total thermal resistance

Figure 12. Comparison of the experimental results at FR 0.75.

Figure 13 shows a comparison of the BHTC based on each variable. As shown, the higher the FR, the smaller the enhancement rate due to the surface modification. At low FRs, film evaporation was dominant. However, at high FRs, the ratio of pool boiling increased slightly due to the large amount of working fluid. Therefore, at low FRs, the inner surface was dry and then rewetted, and the hydrophilic surface rewetted faster than the bare surface. Meanwhile, the effect of surface modification was insignificant at high FRs.

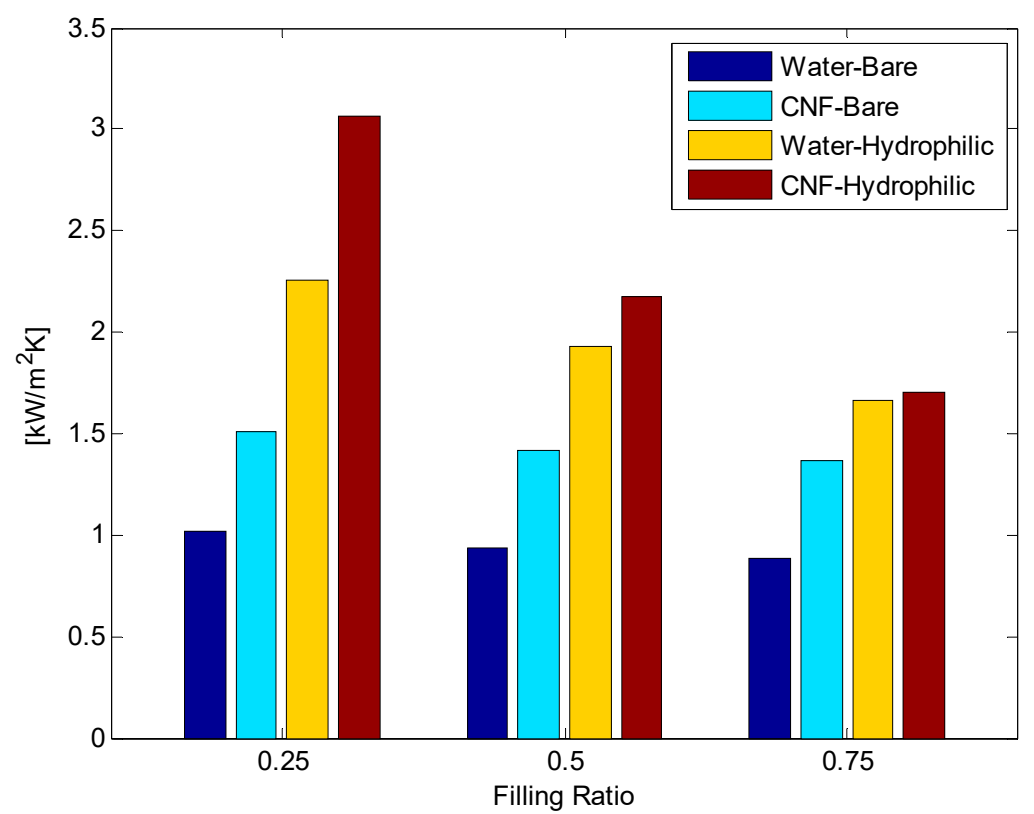

Figure 13. Comparison of boiling heat transfer coefficients. 
Figure 14 shows a comparison of BHTC with Rohsenow's pool boiling theoretical results [25]. Before applying the CNF and the surface modification, the BHTC of this study was much lower than that of Rohsenow's theoretical results because of the Geyser phenomenon. However, after applying the CNF and surface modification, the BHTC showed similar levels. Additionally, Table 4 shows a comparison of the BHTC obtained in this study with those of Noie [26] and Baojin et al. [27], whose Co was 0.108 and 0.120, respectively. Noie [26] and Baojin et al. used water as the working fluid, and the surface modification was not applied. Before applying the CNF and the surface modification, the BHTC of this study was much lower than those of Noie and Baojin et al. because of the Geyser phenomenon. However, after applying the CNF and surface modification, the BHTC showed similar levels. This might have maintained the heat transfer efficiency of the TPCT while increasing Co by reducing the diameter of the TPCT; this is expected to be applicable to applications requiring more compact TPCTs in the future.

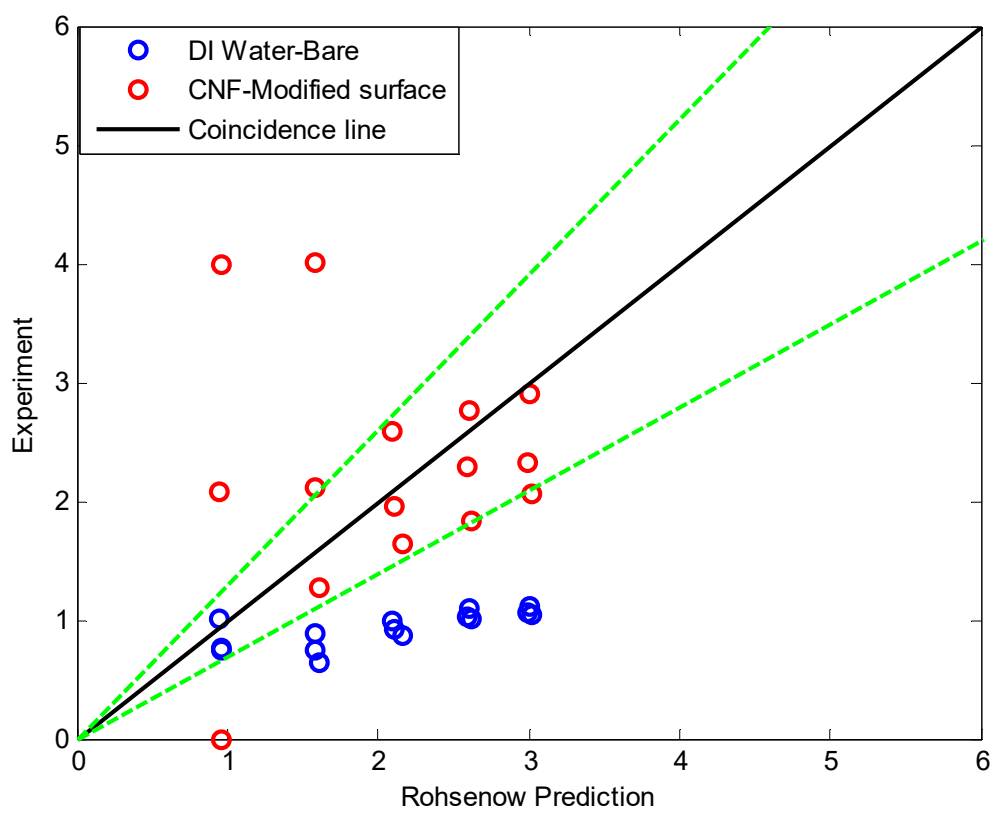

Figure 14. Comparison of boiling heat transfer coefficients with the Rohsenow correlation.

Table 4. Comparison with other studies.

\begin{tabular}{|c|c|c|c|c|c|}
\hline $200-500 \mathrm{~W}$ & $\mathrm{Le} / \mathrm{Lc}(\mathrm{mm})$ & Di (mm) & Co & FR & BHTC $\left(\mathrm{W} / \mathrm{m}^{\wedge} 2 \mathrm{~K}\right)$ \\
\hline & & & & 0.25 & 893-1114 \\
\hline This study & & & & 0.5 & $746-1055$ \\
\hline with water and bare tube & & & & 0.75 & 649-1036 \\
\hline & $300 / 350$ & 11 & 0.245 & 0.25 & $2581-4008$ \\
\hline $\begin{array}{l}\text { This study } \\
\end{array}$ & & & & 0.5 & $1950-2322$ \\
\hline with CNF and surface modification & & & & 0.75 & $1266-2066$ \\
\hline Noie [26] & $214 / 280$ & 25 & 100 & 0.3 & $880-2250$ \\
\hline Nole [20] & $314 / 380$ & 25 & 0.108 & 0.6 & $1075-3210$ \\
\hline Baojin et al. [27] & $350 / 350$ & 22.5 & 0.120 & 0.36 & $3650-4710$ \\
\hline
\end{tabular}

\section{Conclusions}

The confinement effect occurring in a TPCT with Co $=0.245$ was observed. The confinement effect degrades the heat transfer performance of the device. CNF was applied as the working fluid, and hydrophilic surface modification was applied to the inner surface of the evaporator to improve the heat transfer performance of the system.

The findings of this study are as follows. 
(1) When compared to the water and bare surface case, it was revealed that the CHF improved by at least $14.3 \%$ at all FRs $(0.25,0.5$, and 0.75$)$.

(2) The BHTC improved by up to $348.5 \%$, whereas it improved by $205.33 \%, 134.69 \%$, and $93.55 \%$ on average at FRs of $0.25,0.5$, and 0.75 , respectively. The total thermal resistance showed average reduction rates of $47.51 \%, 36.69 \%$, and $22.56 \%$ at FRs of $0.25,0.5$, and 0.75 , respectively.

(3) In addition, because the aggregation and sedimentation of CNFs did not occur even after repeated experiments over a significant time period, it can be concluded that $\mathrm{CNF}$ mitigated the stability problem of the existing inorganic nanoparticles.

In order to collect a larger amount of solar heat in the same area, there is a method of reducing the diameter of TPCT and increasing the device number to increase the heat transfer area. Although the heat transfer performance decreased due to the confinement effect caused by reducing the diameter beyond the limit point, the heat transfer efficiency and the operating limit could be improved by using surface modification and working fluid. Through this method, it is expected that solar heat collection efficiency can be further increased.

In the future, the experimental apparatus should be improved to enable an input power exceeding $800 \mathrm{~W}$ to verify the CHF. In addition, by applying hydrophobic surface modification to the inner surface of the condenser, not only the overall thermal resistance, but also the effect of the confinement effect are expected to decrease.

Author Contributions: Conceptualization, D.C. and K.-Y.L.; Methodology, D.C. and K.-Y.L.; Validation, D.C. and K.-Y.L.; Formal analysis, D.C. and K.-Y.L.; Investigation, D.C. and K.-Y.L.; Resources, W.H. and G.J.; Data curation, D.C. and K.-Y.L.; Writing—original draft preparation, D.C.; Writingreview and editing, K.-Y.L.; Supervision, K.-Y.L.; Project administration, D.C. and K.-Y.L.; Funding acquisition, K.-Y.L. All authors have read and agreed to the published version of the manuscript.

Funding: This research was supported by the National Research Foundation of Korea (NRF) grant funded by the Korean Government (Ministry of Science, ICT and Future Planning (MSIP)) (no. NRF-2017R1C1B5017640).

Acknowledgments: This work was supported by Korea Hydro \& Nuclear Power Company through the project "Nuclear Innovation Center for Haeoleum Alliance".

Conflicts of Interest: The authors declare no conflict of interest.

\section{Abbreviations}

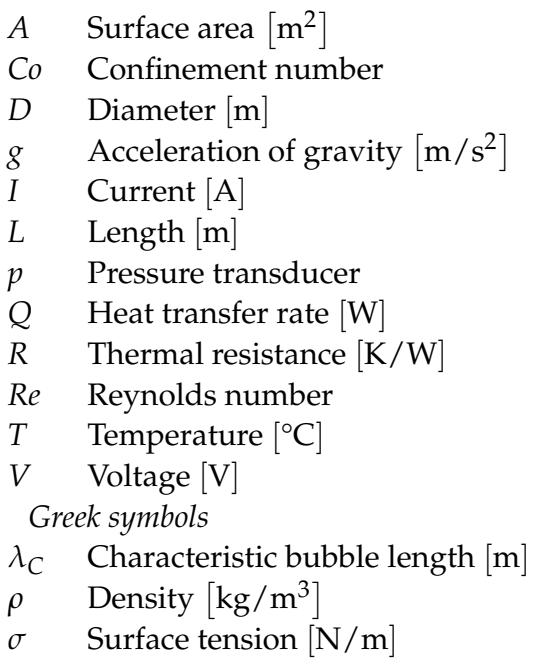




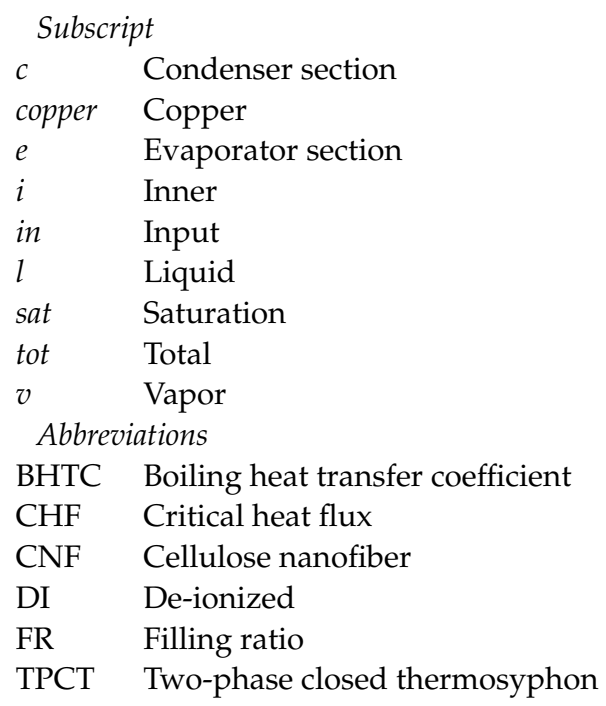

\section{References}

1. Imura, H.; Sasaguchi, K.; Kozai, H.; Numata, S. Critical heat flux in a closed two-phase thermosyphon. Int. J. Heat Mass Transf. 1983, 26, 1181-1188. [CrossRef]

2. Smith, K.; Kempers, R.; Robinson, A. Confinement and vapour production rate influences in closed two-phase reflux thermosyphons Part A: Flow regimes. Int. J. Heat Mass Transf. 2018, 119, 907-921. [CrossRef]

3. Smith, K.; Robinson, A.; Kempers, R. Confinement and vapour production rate influences in closed two-phase reflux thermosyphons Part B: Heat transfer. Int. J. Heat Mass Transf. 2018, 120, 1241-1254. [CrossRef]

4. Robinson, A.J.; Smith, K.; Hughes, T.; Filippeschi, S. Heat and mass transfer for a small diameter thermosyphon with low fill ratio. Int. J. Thermofluids 2020, 1-2, 100010. [CrossRef]

5. Emami, M.R.S.; Noie, S.H.; Khoshnoodi, M.; Mosavian, M.T.H.; Kianifar, A. Investigation of geyser boiling phenomenon in a two-phase closed thermosiphon. Heat Transf. Eng. 2015, 30, 408-415. [CrossRef]

6. $\quad$ Pabón, N.Y.L.; Mera, J.P.F.; Vieira, G.S.C.; Mantelli, M.B.H. Visualization and experimental analysis of Gey-ser boiling phenomena in two-phase thermosyphons. Int. J. Heat Mass Transf. 2019, 141, 876-890. [CrossRef]

7. Khazaee, I.; Hosseini, R.; Noie, S.H. Experimental investigation of effective parameters and correlation of gey-ser boiling in a two-phase closed thermosyphon. Appl. Therm. Eng. 2010, 30, 406-412. [CrossRef]

8. Faghri, A. Review and Advances in Heat Pipe Science and Technology. J. Heat Transf. 2012, 134, 123001. [CrossRef]

9. Choi, D.; Lee, K.-Y. Experimental Study on Confinement Effect of Two-Phase Closed Thermosyphon and Heat Transfer Enhancement using Cellulose Nanofluid. Appl. Therm. Eng. 2020, 183, 116247. [CrossRef]

10. Liu, Z.-H.; Xiong, J.-G.; Bao, R. Boiling heat transfer characteristics of nanofluids in a flat heat pipe evaporator with micro-grooved heating surface. Int. J. Multiph. Flow 2007, 33, 1284-1295. [CrossRef]

11. Truong, B.H. Determination of pool boiling critical heat flux enhancement in nanifluids. Bachelor's Thesis, Massachusetts Institute of Technology, Cambridge, MA, USA, 2007.

12. You, S.M.; Kim, J.H.; Kim, K.H. Effect of nanoparticles on critical heat flux of water in pool boiling heat trans-fer. Appl. Phys. Lett. 2003, 83, 3374. [CrossRef]

13. Vassallo, P.; Kumar, R.; D'Amico, S. Pool boiling heat transfer experiments in silica-water nano-fluids. Int. J. Heat Mass Transf. 2004, 47, 407-411. [CrossRef]

14. Bang, I.C.; Chang, S.H. Boiling heat transfer performance and phenomena of $\mathrm{Al}_{2} \mathrm{O}_{3}$-Water nano-fluids from a plain surface in a pool. Int. J. Heat Mass Transf. 2005, 48, 2407-2419. [CrossRef]

15. Das, S.K.; Putra, N.; Roetzel, W. Pool boiling characteristics of nano-fluids. Int. J. Heat Mass Transf. 2003, 46, 851-862. [CrossRef]

16. Suriyawong, A.; Wongwises, S. Nucleate pool boiling heat transfer characteristics of $\mathrm{TiO}_{2}-$ water nanofluids at very low concentrations. Exp. Therm. Fluid Sci. 2010, 34, 992-999. [CrossRef]

17. Saito, T.; Kimura, S.; Nishiyama, Y.; Isogai, A. Cellulose Nanofibers Prepared by TEMPO-Mediated Oxidation of Native Cellulose. Biomacromolecules 2007, 8, 2485-2491. [CrossRef]

18. Rahimi, M.; Asgary, K.; Jesri, S. Thermal characteristics of a resurfaced condenser and evaporator closed two-phase thermosyphon. Int. Commun. Heat Mass Transf. 2010, 37, 703-710. [CrossRef]

19. Zhao, Z.; Jiang, P.; Zhou, Y.; Zhang, Y.; Zhang, Y. Heat transfer characteristics of two-phase closed thermosy-phons modified with inner surfaces of various wettabilities. Int. Commun. Heat Mass Transf. 2019, 103, 100-109. [CrossRef]

20. Kim, Y.; Kim, J.S.; Shin, D.H.; Seo, J.H.; You, S.M.; Lee, J. Effects of hydrophobic and superhydrophobic coatings of a condenser on the thermal performance of a two-phase closed thermosyphon. Int. J. Heat Mass Transf. 2019, 144, 118706. [CrossRef]

21. Kim, Y.; Shin, D.H.; Kim, J.S.; You, S.M.; Lee, J. Effect of sintered microporous coating at the evaporator on the thermal performance of a two-phase closed thermosyphon. Int. J. Heat Mass Transf. 2019, 131, 1064-1074. [CrossRef] 
22. Keller, A.A.; Wang, H.; Zhou, D.; Lenihan, H.S.; Cherr, G.; Cardinale, B.J.; Miller, R.; Ji, Z. Stability and aggrega-tion of metal oxide nanoparticles in natural aqueous matrices. Environ. Sci. Technol. 2010, 44, 1962-1967. [CrossRef]

23. Prasher, R.; Evans, W.; Meakin, P.; Fish, J.; Phelan, P.; Keblinskia, P. Effect of aggregation on thermal conduction in colloidal nanofluids. Appl. Phys. Lett. 2006, 89, 143119. [CrossRef]

24. Coleman, H.W.; Steele, W.G. Experimentation and Uncertainty Analysis for Engineers; John Wiley \& Sons: New York, NY, USA, 1999.

25. Rohsenow, W.M. A method of correlating heat transfer data for surface boiling of liquids. Trans. ASME 1952, 74, 969-976.

26. Noie, S. Heat transfer characteristics of a two-phase closed thermosyphon. Appl. Therm. Eng. 2005, 25, 495-506. [CrossRef]

27. Baojin, Q.; Li, Z.; Hong, X.; Yan, S. Heat transfer characteristics of titanium_water two-phase closed thermosy-phon. Energy Convers. Manag. 2009, 50, 2174-2179. [CrossRef] 